\title{
Minimum Wage Law for Domestic Workers : Impact Evaluation of the Indian Experience
}

\author{
Rohan Ravindra Gudibande
}

Arun Jacob

Working Paper 5 | 2015 


\title{
Minimum Wage Law for Domestic Workers : Impact Evaluation of the Indian Experience *
}

\author{
Rohan Ravindra Gudibande ${ }^{\dagger} \quad$ Arun Jacob ${ }^{\ddagger}$
}

First version: January 1, 2014

Current version: April 7, 2015

Working Paper 5 | 2015

\begin{abstract}
We conduct an impact evaluation of the minimum wage legislation for domestic workers that was introduced in four states in India over the period of 2004-2012. Combining the matching and differencein-difference estimation strategies we estimate both the short-run and long-run impacts of the legislation on real wages and on employment opportunities. Our results show a positive impact of the legislation on real wages in the short-run, albeit of very small magnitude.However, the legislation seems to have no impact on real wages in the long-run. Further, the legislation did not seem to have had any impact on the extensive margin in terms of employment opportunities or the probability of being employed as a domestic worker in both the short and long run. Our conclusion is that minimum wage legislation for domestic workers need not improve the living standards of workers unless accompanied by strong enforcement mechanisms. To our knowledge, this is the first attempt at quantitatively evaluating the impact of minimum wage legislation for domestic workers in India.
\end{abstract}

Keywords:Wages; minimum wages; labour demand; domestic workers;India; trade unions ; unemployment; informal sector

JEL Classification numbers: J31 J33 J16 J51 J64 J83 J08 J48 O15

\footnotetext{
*Thanks to Jean-Louis Arcand, Arnab Basu, Ugo Panizza, Kristen Sobeck, Vidhya Soundararajan, Lore Vandewalle, and participants at various conferences, including the ILO research department seminar for helpful discussions and comments.The findings, interpretations and conclusions expressed herein are those of the author(s) and do not necessarily reflect the views of the United Nations or its member states. All errors are ours.

$\dagger$ Graduate Institute of International and Development Studies, Geneva, Switzerland. E-mail: rohan.gudibande@graduateinstitute.ch

${ }^{\ddagger}$ Graduate Institute of International and Development Studies, Geneva, Switzerland \& United Nations Conference on Trade and Devleopment (UNCTAD), E-mail: arun.jacob@graduateinstitute.ch
} 
(c) The Authors. All rights reserved. Working Papers constitute research in progress by the author(s) and are published to elicit comments and to further debate. No part of this paper may be reproduced without the permission of the author(s). 


\section{Introduction}

There are more than four million domestic workers in India as per the latest official statistics (NSS 2011). Domestic household workers are one of the few occupational groups not yet covered by national minimum wage law in India despite a lot of debate regarding the same at the national level.Despite resistance domestic services is slowly being accepted as an important informal source of employment worldwide. In 2011, the ILO passed a convention on decent work for domestic workers but India has not yet ratified this convention ${ }^{1}$. In India one of the primary reasons for the non inclusion of domestic services sector under the National Minimum wage act of 1948 has been the fact that it is a very personalized (informal) service within a private household. However, after renewed struggle by the domestic workers and their unions, some states in India (given below) have included the domestic services under their list of sectors covered by minimum wage laws over the past few years.

We conduct an impact evaluation of the minimum wage law legislation for domestic workers introduced in four states in India over the period of 2004-2012. Four states in India, namely Andhra Pradesh (AP), Bihar, Karnataka and Rajasthan, instituted minimum wage legislation for domestic workers between 2004 and 2009. Using four rounds of the national sample survey (NSS), combining the matching and difference-in-difference estimation strategy we analyze the impact of the minimum wage law in both short-run and in long-run. We find positive impact of the legislation on real wages in the short-run, while this impact seems to attenuate by 2012. There seems to be no impact of the legislation at the extensive margin on the employment opportunities or on the probability of being employed as a domestic sector worker in both short and long-run. Even in the short run, the magnitude of impact on real wages seems to be rather small. We attribute the reason for this small and short-lived impact on poor law enforcement and weak monitoring mechanism that accompanied the law. Hence, the key policy message of our paper is that domestic sector workers need a lot more than just minimum wage legislation (to make any real positive impact on their livelihood and well being as determined by there wages). To our knowledge, this is the first paper to empirically determine the impact of minimum wages on domestic workers in India.

The rest of the paper is divided into four sections. Section 2 will give an overview of the literature on minimum wages. Section 3 will discuss the domestic work sector in India. Section 4 will describe the empirical methodology used in the paper. Section 5 will provide our estimation results and section 6 will describe some robustness checks and sensitivity analysis that reaffirms our results. Section 7 will provide some discussion of our main results, their policy implications and some pointers for future research.

\footnotetext{
${ }^{1}$ ILO Website-http://www.ilo.org/
} 


\section{Literature review}

There is a large empirical literature on the general impact of minimum wage policy using firm level data. For example Ashenfelter and Smith [1979] states that firm's compliance with minimum wage law in the United States was about 55 percent in 1975. Neumark and Wascher [1992] uses panel data on state minimum wages to predict that a 10 percent increase in minimum wages causes a 1 to 2 percent decline in the employment for teenagers and 1.5 to 2 percent decline for young adults. Card and Krueger [1994] studies the 1992 New Jersey minimum wage increase and found that there was an increase in employment. Neumark and Wascher [1995a] re-evaluates the evidence from Card and Krueger [1994] New Jersey-Pennsylvania minimum wage experiment using data from actual payroll records from 230 fast food restaurants.The author conclude contrary to Card and Krueger [1994] and finds that the New Jersey minimum wage increase led to a 4.6 percent decrease in employment.Another paper by Neumark and Wascher [1995b] studies the impact of minimum wages on the disemployment of teenagers who were both high skilled and low skilled.The authors find that although minimum wages have small net effects on overall teen employment rates,the increase in employment raised the probability that more skilled teenagers leave school and thereby displace lower skilled workers from their jobs. The authors further find that the displaced low skilled workers are more likely to remain unemployed.

Card and Krueger [1998] in response to Neumark and Wascher's 1995 findings re-examine the effect of the New Jersey minimum wage law using the Bureau of Labour Statistics(BLS) data over the period of their original 1994 study to find that the BLS fast food data set indicates slightly faster employment growth in New Jersey than in the Pennsylvania border counties though the difference is small and statistically insignificant.After comparing all the data sets from BLS, their original survey data from the 1994 paper and Neumark and Wascher [1995a] payroll data, Card and Krueger conclude that the New Jersey Minimum wage Law in April 1992 had little or no systematic effect on total fast-food employment in the state, despite some restaurants witnessing an increase in employment while others witnessing a fall in employment as a response to the minimum wage.

Lang and Shulamit [1998] using a simple model of bilateral search with heterogenous workers as a theoretical framework show empirical evidence that while minimum wage law increases employment,there are distributional consequences such as shifting of employment from adults to teenagers and students using the NBER current population survey extracts. Michael Baker and Stanger [1999] examine the effects of minimum wage legislation in Canada over the period 1975-93 and find that for teenagers a 10 percent increase in the minimum wage is associated with roughly a 2.5 percent decrease in employment. Arindrajit Dube and Reich [2010] using policy discontinuities at state borders to identify the effects of minimum wages on earnings and employment in restaurants and other low wage sectors find no adverse or negative employment effects.

David Neumark and Wascher [2013] in response to studies which shows no effect of minimum wage laws on employment (using research designs intended to control for spatial heterogeneity) the authors 
(using a method which let the data identify the appropriate control groups) find evidence for disemployment effects and show that minimum wages pose a tradeoff between higher wages to some people against job losses for others.Dube et al. [2007] evaluates the effects of San Francisco's adoption of an indexed minimum wage in 2004 and shows an increase in wages,decline in wage inequality and no employment loss. The previous studies mainly focused on developed countries. There are other papers which focus on developing countries. Bell [1997] uses yearly data on wages and employment for Mexico and Columbia and finds a positive impact on wages and negative effects on employment. Other papers such as Gindling and Terrell [2007] finds a negative impact on employment due to implementation of minimum wage.Almeida and Carneiro [2005] show that in Brazil firm employs a smaller amount of informal workers in areas where the enforcement of minimum wage law is stricter.Almeida and Carneiro [2007] show that strict enforcement leads to higher employment and low wage premium in Brazil. More recently Ronconi [2008] found higher enforcement decreases non enforcement of minimum wage laws in Argentina but Almeida and Carneiro [2011] find at the municipal level in Brazil an increase in labour inspections informal employment declines, unemployment rises and wages at the top of the formal wage distributions declines.

There is also no dearth in theoretical literature trying to predict the general impact of a minimum wage law. Most theories predict a uniform negative effect of minimum wages on employment in competitive labour markets and an inverted U-shaped relationship in monopsonistic and oligopsonist models [Soundararajan, 2013]. Basu et al. [2010] develop an incentive compatible equilibrium model which predicts the response of employment to a minimum wage rise as either positive, negative or subdued given the level of minimum wage and enforcement. Hence summarizing the general literature (both theoretical and empirical) we observe that in perfect labour markets a) there is generally a positive impact of minimum wage law on wages without accounting for enforcement, b) a negative impact on employment without enforcement and c) ambiguous impact on employment when we account for enforcement. However the literature shows that in case of imperfect markets especially in the informal sector, we generally find a non linear impact of minimum wage law on employment and wages [Soundararajan, 2013].

The literature on the impact of minimum wage laws on the Domestic Work informal sector is very limited. Dinkelman and Ranchhod [2012] using difference in difference approach for South African data find a) if pre law wage was below the minimum wage then there was an increase in wage, b) on average wages rose 13 to 15 per cent in provinces with a mean wage gap, c) the wage response to the law was positive despite absence of full compliance, d) significant improvement in conditions of work across the domestic work sector and e) there was insignificant impact on employment. On the whole the authors argue that they have shown evidence that labour market regulation in the informal sector can have a real and immediate impact despite imperfect enforcement and limited compliance in the short run. Mattila [1973] show that households are very quick to find substitutes as relative costs of maids increases due to minimum wage laws if implemented in the USA. This basically suggests that minimum wage law has a negative impact on domestic worker employment. 


\section{Domestic work sector in India}

The Minimum Wages Act of India,1948 legally grants a minimum wage for workers in many industries and periodically fixes minimum wages for those workers employed in activities listed in the "employment schedule" of the government [Soundararajan, 2013]. The government could be both at the state or at the central level. This is because under India's federal government system, the labour ministry's programs are in the concurrent list which enables both the central and state governments to initiate, implement and share responsibility with regard to labour laws [Neetha, 2009].The law is applicable to both informal and informal sectors as long as the activity belongs to the employment schedule list.

Besler and Rani [2010] find that the central government and state governments together set about 1171 different minimum wage rates (with 48 belonging to the centre and 1123 belonging to the state governments $)^{2}$ The implication then is that domestic worker cannot take the help of labour laws or labour courts in case of dispute with the employer. This implicitly excludes domestic workers from the National Minimum Wages Act (NMW),1948 [Neetha, 2009].

ILO report titled "Moving Towards Decent Work for Domestic Workers" [D'souza, 2010] cites the fact that many countries either explicitly exclude domestic work from the ambit of labour legislation or make very little provisions to address the needs of domestic workers. The report also highlights the fact that in the case of the relationship between employer and the domestic worker there is an intrinsic difference when compared to other occupations. The main characteristic differences between domestic work and other similar low skilled informal occupations are the following [D'souza, 2010] i) the employment relationship is invisible or in other words it is often undeclared and has no written contract involved ; ii) there is an unequal balance of power between employer and employee; iii) lack of precise job description and iv)the expectation on the part of the employer to be available at all times. With regard to India, almost two to three percent of the India's workforce are involved in domestic work especially groups which are considered vulnerable such as tribal or Adivasi. These groups are classified as Schedule Tribes and Schedule Castes by the constitution of India. Furthermore India has not yet ratified the ILO's Domestic Workers Convention,2011 (No.189) which came into force in 2013. This convention which became a binding international law from September 5th 2013 extends basic labour rights to domestic workers around the globe.

The reasons for the exclusion of domestic workers from NMW can be traced from the various debates in the parliament since 1959 [Neetha, 2009]. Some of the arguments against the enforcement of minimum wage for domestic workers are the following namely [Neetha, 2009, Armacost, 1994], a) large scale loss of employment opportunities of domestic workers and b) the difficulty in enforcing the laws protecting the minimum wage of the workers due to location of work being private space and c) the informal employment relation between the domestic worker and the private household.

\footnotetext{
2 Domestic workers are excluded from the coverage of many core labour laws as they are not considered either as "work men", "employer" or an "establishment" at an all India level.
} 
However, off late the pressure on the Indian state to respond to the issues of domestic workers has become more intense. This has led to differing response from across states in India. For example, another ILO report [Eluri and Singh, 2013] documents the case of a strong grass roots movement across Karnataka in pressurizing the government in implementing minimum wages for domestic workers. For example the study analyzes the process of formation of the Karnataka Domestic Workers Congress and Domestic Workers Brigade and their role in organizing domestic workers (especially women in urban city of Bangalore) towards demanding better legal wages. It also provides insights into the challenges encountered in unionizing informal women workers and reflects on how to implement such unionization of informal workers across India. One of most important intervention has been the inclusion of domestic workers in the list of scheduled employment under the Minimum Wages Act of 1948 in a few states of India [Neetha, 2013]. Such a legal extension recognizes the private households as workplaces making it an important legal change in the concerned states . There are a total of seven states where the minimum wages for domestic workers has been implemented ${ }^{3}$ Of of these states we focus our analysis on Karnataka which was the first to do it in 2004 followed by Bihar and AP in 2007 and Rajasthan in 2008 4. It was only in Karnataka and Andhra Pradesh, that unions and organizations working among domestic workers played a key role in bringing the sector under the purview of the Act. ${ }^{5}$

All these states define domestic work in terms of tasks undertaken and the tasks are listed in their respective minimum wage notification. This might be an easy route but this risks the exclusion of many tasks that are carried out by domestic workers from the list and hence will be underpaid when compared to the notified minimum wages. The tasks listed in the notification vary from state to state. None of the tasks thus classified in the minimum wage notification (MWN) in any of the states we are considering in our analysis were termed as skilled. Hence there was no real impact in reversing the deskilling and devaluation of domestic workers by the society at large across the treated states.

The notifications on the minimum wages in Karnataka, AP, Bihar, Rajasthan ${ }^{6}$ reveal that the definition of paid domestic work which was commonly shared by trade unions,organizations of domestic workers, employers and labour officials across the states was not rooted in the employment relationship which governs this sector but in the societal understanding of domestic work [Neetha, 2013]. In other words

\footnotetext{
3 Karnataka, Kerala, Andhra Pradesh (AP), Bihar, Rajasthan, Jharkhand and Odisha are the seven states where the minimum wage for domestic workers has been implemented.There are three more states namely Tamil Nadu, Maharashtra and Assam that have included domestic work in their respective state list of scheduled employment in 2007,2008 and 2013 respectively but have not fixed any wage rate.Chhattisgarh (2013), Jharkhand (2011) and Kerala (2011) have also extended Rashtriya Swastya Bima Yojana (RSBY), a health insurance scheme to domestic workers as the first step in widening the coverage of welfare schemes to this occupational group to domestic workers.

4 We exclude Jharkhand from our analysis as the minimum wage law was instituted there only in 2010. Our survey data pertains to 1999, 2004, 2009 and 2012, hence we do not have two post-treatment survey rounds for this state. Hence, we decided to exclude Jharkhand from our analysis. This is also an additional reason for excluding Kerala, which instituted minimum wage law in 2010.

5 However in Rajasthan it was a direction from the Union Ministry of Labour to fix the minimum wages tha initiated the law.

6 We will not be analyzing the impact of minimum wages in Kerala due to the fact that the state witnessed an informal norm of minimum wage standards for domestic workers as early as in 1989 despite the official minimum wage being notified only in 2010 making Kerala a unique case when compared to the treatment states in our analysis.
} 
domestic work is viewed by all share holders (namely government officials ,politicians and employers) as non technical and an unskilled occupation. We further observe that the minimum wage rates are either fixed for an hour or a day as opposed to a monthly calculation. Payment is either on hourly or daily (which is of 8 hours) basis which implies that workers could be a) denied rest days, b)there could be more work intensity , c) a clear lack of focus on the remuneration of live-in workers and d) there is no clear clarification on how to calculate overtime wages.

The wage rates prescribed by NMW does not suggest any clear method of calculation though the minimum wage notifications must take into account the skill component of the tasks as well as the requirements of the workers. The arbitrariness in fixing the minimum wage rates is shown in the fact that Bihar has the lowest rates while Karnataka has the highest if daily and monthly wages are considered. In AP, Rajasthan and Bihar all tasks have the same minimum wage while Karnataka has two seperate wage rates with housework with child care commanding higher rates.One advantage of having hourly wages is that there can be a differentiation between part time and full time daily work, but this is not the case with the way the minimum wages that have been set in the four states. In conclusion,we can infer that the minimum wages fixed are unclear due to the arbitrary nature of the calculations and how domestic work has been defined.

Table 1: Comparing Domestic Minimum wages to Other Informal Sectors Between Treatment States

\begin{tabular}{rccc}
\hline & Domestic Minimum Wage & \multicolumn{2}{c}{ Other Minimum Wage } \\
\hline States & Cleaning Workers & Hotel Workers \\
Karnataka & 165.58 & 195.38 & 196.70 \\
Andhra Pradesh & 173.85 & 260.56 & 229.83 \\
Bihar & 144.62 & 157 & 157 \\
Rajasthan & 144.73 & 147 & 147 \\
\hline Notes : All minimum wages is for 8 hrs daily rate \\
The domestic minimum wages are for all household tasks including childcare \\
The figures are updated as of December 2012 \\
The minimum wage for Sweeping and Cleaning Workers in Karnataka is an inter-state average \\
\hline
\end{tabular}

Furthermore, multiple task based fixing of minimum wage makes the calculations even more complicated. Table 1 shows that compared to the minimum wages for similar work outside private households, domestic workers get much lower minimum wage for the same job. This is true across the four states. This uniformity might be due to the devaluation of house-work as a non productive work in an unproductive work-space [Sankaran, 2013]. Sankaran [2013] further points to the fact that domestic wage minimum wage law is focused too much on wage rates with a little focus on the valuation of unpaid care and on the inequalities faced by women who perform household labour compared to their men counterparts. He further points out that the minimum wages of domestic workers does not account for the provisions of the Equal Remuneration Act (ERA), 1976 which tries to prevent discrimination of men and women.According to the minimum wages notified, a domestic worker will have a monthly earning of Rs. 3583 in Bangalore (Karnataka), Rs. 3260 in Hyderabad (AP), Rs 3133 in Jaipur (Rajasthan), Rs 2712 
in Patna (Bihar). These monthly wages for domestic workers are much less than the minimum wages earned by workers from other informal sectors. In the section that follows we describe the methodology and the data sources we use to measure the impact of minimum wage legislation in these four states in India.

\section{Impact Evaluation Methodology}

\subsection{Data}

We use the 55th, 60th, 66th and 68th rounds of National Sample Survey of India, which corresponds to 1999, 2004, 2009, 2012 respectively. Hence, we have two survey years prior to the treatment and two surveys post treatment for all the four treatment states that we analyse. ${ }^{7}$ The survey covers the whole of the Indian Union except (i) interior villages of Nagaland situated beyond five kilo metres of the bus route and (ii) villages in Andaman and Nicobar Islands which remain inaccessible throughout the year. The sample size at state level is in proportion to its population and at least 16 first stage sampling units at both rural and urban areas of each stage are included. This allows us to study impact of public policies at state level.

\subsection{Sample selection and key variables}

Before heading on to the main empirical strategy, it will be interesting to look at the summary statistics of the data used in the paper. Table 21 in the Appendix compares the sample means for all the Indian States before and after treatment. For our key dependent variables namely (log) real wages and months unemployed we observe the following namely i) mean real wages sharply increase for all states in the post law period compared to pre-law period and the difference is significantly different from zero and ii) mean months unemployed seem to be significantly declining between post law and pre law period indicating an increase in employment for domestic workers. Now looking at Table 22 in the Appendix which compares the means before and after treatment only for the treatment states. Again focusing on our key dependent variables we observe that while the mean real wages increase significantly in post law period, the months unemployed decline significantly in post law period again indicating an increase in employment for domestic workers after the treatment. In order to facilitate comparison between treatment and control states we show the control and treated states on a map of India in Figure 3 of appendix. Further, tablel 26 of appendix provides a snapshot of the key socioeconomic indicators of the treatment states.

\footnotetext{
7 We exclude Jharkhand from our analysis as the minimum wage law was instituted only in 2010. Our survey data pertains to 1999, 2004, 2009 and 2012, hence we do not have two post-treatment survey rounds for this state. This is also an additional reason for excluding Kerala, which officially notified minimum wages only in 2010 .
} 
From the summary statistics one can could easily conclude (especially from Table 22) that there was an increase in mean real wages and decline in the mean months unemployed after treatment in treatment states. However these summary facts despite being suggestive does not account for the heterogeneity in the impact of the law across the treated and untreated states in our sample. Our attempt in the rest of the paper is to isolate the impact of the domestic wage legislation through the observed changes in the outcome variables (wages and unemployment) and see if the increase in wages or decline in unemployment in the treated states is significantly different from that of comparable members in a control group both in the long and the short run.

Now comparing the means before and after the law for our covariates we observe the following i) when we include all states, barring the type of caste the individual belonged to,all the covariates are significantly different from each other; ii) when we include only the treatment states we find that the ownership of land, possession of land, being an ST, marital status and being just literate remains unchanged before and after treatment; iii)the proportion of illiterate and OBCs (or other back ward castes) is quite high among our domestic worker sample both while looking at the full sample for treatment states only; iv) the proportion of females (which is coded as 0 ) is higher than the males in our domestic worker sample both in treatment states and otherwise and v) the mean age of domestic workers in our sample (both for treated and the non treated states) seem to be around 35 years before treatment and 38 years after treatment.

Within the NSS surveys, there is an indicator under the enterprize type which identifies 'private households employing maid servant, watchman, cook, etc.', where all the workers in this category can be safely classified as domestic workers. The wage rate, is the total weekly wages received (both cash and in kind) in the previous week. We convert nominal weekly wages into real wages based on 2004 price levels ${ }^{8}$ Hence our main outcome variable is log real wage. We also study the impact of the legislation on unemployment. For the unemployment variable, approximate number of months without work in the previous year is used as the measure. The matching procedure is done based on the following variables : gender, age, marriage status, whether belongs to scheduled caste (SC), scheduled tribe (ST), or other backward classes (OBC), level of education (illiterate, just literate, primary, secondary or post-secondary education), land owned and land possessed by the household.

As explained earlier, we restrict our analysis of the impact of the minimum wage law for Domestic Workers to urban areas in the state of Karnataka, Andhra Pradesh, Bihar and Rajasthan ${ }^{9}$.

8 We use the food price index of the urban industrial workers provided by the Reserve Bank of India to convert nominal wages to real wages.

9 We do not include rural areas for the following reasons (i) Due to the problems of enforceability of minimum wage in rural areas (ii) the National Rural Employment Guarantee Scheme (NREGS), which guarantees 100 days of employment in rural areas, was introduced in many of the districts within these states since 2005. The scheme would have had some impact on domestic workers in these rural areas as they were most likely to enroll in NREGS work simultaneously. Hence by including rural areas we run the risk of not able to distinguish between the impact of NREGS from that of the minimum wage legislation. (iii) in rural areas, domestic workers also do agricultural work and some of their tasks cannot be distinguished from agricultural laborers and sometimes they are paid mostly in kind and making the wage measures increasingly prone to errors. 


\subsection{Empirical Strategy}

As explained in the earlier sections, between 2004 and 2012, five states instituted minimum wage laws for domestic workers namely : Karnataka (2005) ${ }^{10}$, Bihar (2007), Andhra Pradesh(2007), Rajasthan (2008). We have two rounds of surveys (1999 and 2004 rounds) before the law was instituted and two rounds of survey (2009 and 2012 rounds) after the law came into effect in four states (Andhra Pradesh, Bihar, Karnataka and Rajasthan).

Our primary estimation strategy is a difference-in-difference approach for our outcome variables between the treatment and control groups. The following difference-in-difference empirical model is adopted.

$$
y_{i s t}=\alpha_{0}+\alpha_{1} * \text { Post }_{t}+\alpha_{2} * \text { treatmentstates }_{\text {st }}+\alpha_{3} * \text { treatmentstates }_{\text {st }} * \text { Post }_{t}+\gamma * X_{\text {ist }}+\epsilon
$$

$y_{\text {ist }}$ corresponds to different outcome variables of interest at the individual level, $* X_{\text {ist }}$ represents different control variables that includes age, sex, education level, land owned or possessed by household and the caste category. In addition, we also use the interactions between these control variables in some of the specifications. Post $t_{t}$ is a dummy indicating the post treatment period. $\alpha_{3}$ gives us the differencein-difference estimator for our outcome variable of interest.

We use entropy balancing (represented as ebalance in our estimation tables) as described in [Hainmueller, 2012] to ensure covariate balancing of first three moments of covariates between the treatment and control groups. This is achieved through a data pre-processing methodology that relies on maximum entropy re-weighting scheme that calibrates unit weights so that the re-weighted treatment and control groups have balanced moments in terms of all covariates. [Hainmueller, 2012] finds that this procedure can greatly reduce model dependence of estimation of treatment effect.

We also adopt a combination of matching and difference-in-difference approach to estimate the impact of the minimum wage law legislation in these states. For domestic workers in the treatment states (those instituted minimum wage legislations), we find counterparts in the same states (treatment states) and non-treatment states, both before and after treatment through a matching procedure. The difference in difference of the outcome variables between these treatment and control group members before and after the treatment, gives us a measure of the impact of the minimum wage legislation.

The main advantage of combining the matching and difference-in-difference methods (MDID) is to weaken the underlying assumptions of these two methods used separately. MDID adopts a common trends assumption- had the treated remain untreated they would have experienced the same change in outcomes as that of the control groups [Blundell and Dias, 2009]. Let $t$ and $t^{\prime}$ be the time period before and after treatment respectively, $X$ the observable characteristics, $D=1$ indicates selection for treatment.

10 In Karnataka, Domestic work was removed from the scheduled list under the Minimum Wages Act in the state of Karnataka in 1993, a year after it was first included. Though the minimum wages act was notified in 2004, it is only in June 2005, Karnataka again brought 'domestic work' back into the schedule [Neetha, 2009]. So for the purpose of this study the treatment tookplace in Karnataka in June 2005. 
$Y_{0}$ represents the outcome variable in the untreated state. So the underlying parallel trends assumption of MDID and our basic difference-in-difference estimation strategy translates to the following.

$$
E\left(Y_{0 t}-Y_{0 t^{\prime}} \mid X, D=1\right)=E\left(Y_{0 t}-Y_{0 t^{\prime}} \mid X, D=0\right)
$$

In addition to the parallel trends assumption, MDID also require the following common support assumption.

$$
P\left(D_{i t^{\prime}}=1 \mid X, t\right)<1
$$

With repeated cross section data (like in our case), we need to ensure that the treatment group members have comparable counterparts in all the three control groups namely- the treated before treatment, untreated both before and after treatment. By estimating treatment effect on the treated by matching in the region of common support we are able to reduce the bias due to non-overlapping support. ${ }^{11}$

Heckman et al. [1997] cites some additional advantages of MDID. It reduces the bias induced by different questionnaires likely to be used for treatment and control groups as well as the bias caused by differing local market characteristics of the control and treatment groups ${ }^{12} .{ }^{13}$

The matching estimator of the treatment effect, $\alpha^{M D I D}$, can be represented as [Blundell and Dias, 2009, Heckman et al., 1997] :

$$
\alpha^{M D I D}=\sum_{i \epsilon T_{1}}\left\{\left[y_{i t^{\prime}}-\sum_{j \epsilon C_{1}} \varpi_{i j t^{\prime}}^{C} y_{i t^{\prime}}\right]-\left[\sum_{j \epsilon T_{0}} \varpi_{i j t}^{T} y_{i t}-\sum_{j \epsilon C_{0}} \varpi_{i j t}^{C} y_{i t}\right]\right\} \omega_{i}
$$

where $\left(T_{0}, T_{1}, C_{0}, C_{1}\right)$ denotes the treatment and control groups before and after the treatment and $\varpi_{i j t}^{G}$ represents the weight attributed to individual $j$ in group $G$ and time $t$ when compared with the treated indivdual $i, \omega_{i}$ accounts for the reweighting that reconstructs the outcome distribution for the treated sample.

To support the MDID approach, we also do a Kolmogrov-Smirnov test on the distribution of outcome variables both before and after treatment through estimating the distributions through non-parametric kernel density approach.

In addition to the above estimations of impact of treatment. We also study the impact of treatment intensity. In the minimum wage literature, the treatment intensity is most commonly quantified in terms of wage gap (WG), which is the difference between the newly instituted minimum wages and the median wages in the pre-treatment period. The median weekly wages for treatment states appear to be substantially lower than the instituted minimum wage rates. ${ }^{14}$

We adapt the difference-in-difference methodology described in earlier sections to take into account the impact of wage gap on the outcome variables using the following empirical model.

11 One limitation of this approach is that this estimator is inherently different from that of an experimental RCT setup, here we are able to estimate only the treatment effect on treated who falls in the region of common support

12 These could be potentially very important source of bias as exemplified by Heckman et al. [1998]

13 In our case, both treatment and control group members were instituted the same survey questionnaires.

14 We calculated the weekly minimum wages using 8 hours work per day and 7 work days per week. To construct wage gap, the median weekly wages of each state for the pre-treatment year 2004 were used. 


$$
y_{i s t}=\alpha_{0}+\alpha_{1} * \text { Post }_{t}+\alpha_{2} * W G_{s t}+\alpha_{3} * W G_{s t} * \text { Post }_{t}+\gamma * X_{i s t}+\epsilon
$$

Similar to the earlier equations (1 and 2), $\alpha_{3}$ gives us the difference-in-difference estimate of the impact of treatment intensity on our outcome variables. If $\alpha_{3}$ is positive and significant it implies that the states with higher treatment intensity (WG) registered higher increase in outcome variable.

\section{Results}

\subsection{Aggregate Results : Short-Run Impacts}

We analyse the impact of the minimum wage legislation for domestic workers on two main outcome variables: log real wages and unemployment. For both these outcome variables we study the impact using three approaches explained earlier : normal difference-in-difference, entropy balancing (ebalance), matching with diff-in-diff (MDID). We begin by studying the short-term impact of the minimum wage legislation using 2004 as the baseline and 2009 survey round as the post-treatment period. In Andhra Pradesh, Bihar, Karnataka and Rajasthan the treatment took place between 2004 and 2009. Thus, studying the impact of legislation in 2009 permits us to gauge the short-term impact of the legislation.

Table 2 provides the estimations for normal difference-in-difference (DiD) estimations and entropy balance (ebalance) clubbed along with DiD estimations for all four of treatment states. As discussed in the earlier section, entropy balancing helps to re-weight data such that treatment and control groups matches in terms of distributional properties ${ }^{15}$. We find statistically significant positive impact under ordinary DiD and entropy balance procedures on real log wages in these treatment states. The covariates affect the real wages in the expected direction. For example, belonging to lower caste implied you earned lower wages, while more educated workers received higher wages compared to less educated counterparts. We also provide a specification that includes all interactions between covariates as controls. The reason for conducting regressions with interactions is that some of these interactions will have very significant impact on determining the wage rates. For instance, gender and caste interaction term will help capture any additional discrimination faced by women of lower caste, compared to their higher caste counterparts. Various economic, social and cultural dimensions enters the calculation of domestic sector workers [Sengupta and Sen, 2013] and these interaction terms help to capture several of such factors. Our estimations prove that many of these interactions are significant in determining the bargaining power and hence the wage levels of domestic sector workers. The positive impact of minimum wage legislation holds even in this specification which includes all interactions between covariates.We also run DID and ebalance estimations by including a) state dummies separately ,b) with city dummies separately,c)with state dummies and interaction terms and d) with city dummy and interaction terms.For all these specifications we a significant and a positive impact of the minimum wage legislation on the real

15 the tables depicting the matched moments between the control and treatment group can presented on request 
weekly wages. The magnitude of the impact is also very similar ${ }^{16}$.

We also test the impact of the legislation on unemployment, by adopting similar estimation strategies. However, we find no statistically significant impact of the legislation on unemployment.

Table 2: Short Run : Impact on Real Wages

\begin{tabular}{lcccc}
\hline Outcome Variable : & Log Real Wages & Log Real Wages & Log Real Wages & Log Real Wages \\
Estimation : & DiD & DiD & E-balance \& DiD & E-balance \& DiD \\
Post & -0.03 & -0.04 & -0.02 & -0.01 \\
& 0.05 & 0.05 & 0.04 & .05 \\
Treatment states & -0.08 & -0.11 & -0.10 & $-0.01^{* *}$ \\
& 0.05 & 0.05 & 0.07 & .05 \\
Post*treatment states & $0.30^{* * *}$ & $0.28^{* * *}$ & $0.28^{* * *}$ & $0.28^{* * *}$ \\
& 0.10 & 0.10 & 0.09 & .08 \\
Controls & Yes & Yes & Yes & Yes \\
Interactions & No & Yes & No & Yes \\
N & 1764 & 1764 & 1764 & 1763 \\
R2 & 0.244 & 0.303 & 0.323 & 0.358 \\
\hline Standard errors clustered at State level in paranthesis & \\
$* * * * * *$ indicate significance at 1,5 and $10 \%$ significance levels & \\
Control group refers to domestic workers in the non-treated states (excluding Kerala) \\
\hline
\end{tabular}

Table 3: Short Run : Impact on Unemployment

\begin{tabular}{lcccc}
\hline Outcome Variable : & Unemployment & Unemployment & Unemployment & Unemployment \\
Estimation : & DiD & DiD & E-balance \& DiD & E-balance \& DiD \\
Post & $-0.31^{* * *}$ & $-0.31^{* * *}$ & $-0.31^{* * *}$ & $-0.39 * * *$ \\
& 0.10 & 0.11 & 0.09 & .10 \\
Treatment states & -0.07 & -0.06 & -0.20 & -0.09 \\
& 0.22 & 0.23 & 0.17 & .17 \\
Post*treatment states & -0.10 & -0.11 & -0.06 & -0.02 \\
& 0.22 & 0.23 & 0.19 & .22 \\
Controls & Yes & Yes & Yes & Yes \\
Interactions & No & Yes & No & Yes \\
$\mathrm{N}$ & 1829 & 1829 & 1829 & 1829 \\
R2 & 0.015 & 0.038 & 0.026 & 0.070 \\
\hline Standard errors clustered at State level in paranthesis & \multicolumn{3}{c}{} \\
$* * * * * * *$ indicate significance at 1,5 and $10 \%$ significance levels & \\
Control group refers to domestic workers in the non-treated states (excluding Kerala) \\
\hline
\end{tabular}

We then use the MDID approach to study the impact of minimum wage law legislation on the real wages and unemployment of domestic sector workers in all five treatment states combined ( Karnataka (2005), Bihar (2007), Andhra Pradesh(2007) and Rajasthan (2008)). We match the treatment group members with counterparts from these states in the pre-treatment phase and we follow the same procedure for control group members. The matching is carried out in terms of all the covariates used in the normal DiD approach. Since we have cross sectional data, this procedure ensures that difference in difference is estimated using most comparable counterparts across different survey rounds. Table 4 gives

16 Tables not included in the paper.It can provided on request by the authors 
the result of the MDID estimation where we cluster the standard errors ${ }^{17}$. Similar to the case of entropy balancing and DiD, we find significant impact of minimum wage legislation on weekly real wages. Interestingly, the magnitude of the treatment impact is also similar in all the above three procedures, further confirming our conclusions.We also estimate short run MDID results sensitive to clustering the standard errors and additional covariates in the form of i)interactions between all the covariates on which the data is matched and ii) state dummies.All the sensitivity short run MDID estimates results are in the appendix.Table 23 gives the short run MDID estimates where the standard errors are clustered and interactions between all the covariates on which the data is matched are included as controls.Table 24 gives the short run MDID estimates where the standard errors are clustered and state dummies are included as controls.Table 25 gives the short run MDID estimates where the standard errors are clustered and interactions along with state dummies are included as controls.We observe from all the aforementioned sensitivity MDID estimation results when compared to the case in Table 4 and of entropy balancing and DiD, there is a significant positive impact of minimum wage legislation on weekly real wages.The magnitude of the impact is also very similar across the various MDID estimations in the short run.Furthermore we estimate MDID short run estimates with city dummies and the interaction terms as additional covariates (with clustered standard errors) ${ }^{18}$.Like in the previous cases we find a significant impact of minimum wage legislation on weekly real wages with very similar magnitudes.

Table 4: Short Run: MDID Estimation Results-Clustering

\begin{tabular}{crrrrrrl}
\hline & \multicolumn{3}{c}{ Base Line (BL) } & \multicolumn{3}{c}{ Follow Up (FU) } & DiD \\
\hline Outcome Variable & Control & Treated & Diff(BL) & Control & Treated & Diff(FU) & \\
Log real wages & 5.43 & 5.35 & -0.082 & 5.56 & 5.79 & 0.22 & $0.31^{* *}$ \\
& 0.04 & 0.05 & 0.07 & 0.06 & 0.14 & 0.15 & 0.13 \\
Months Unemployed & 0.56 & 0.5 & -0.056 & 0.28 & 0.13 & $-0.15^{*}$ & -0.095 \\
& 0.13 & 0.191 & 0.23 & 0.06 & 0.04 & 0.07 & 0.25 \\
\hline Notes : Clustered robust standard errors reported in paranthesis. \\
Number of clusters is 33 \\
DiD indicates the difference in difference estimate of the outcome variable. \\
Significant at 90(*), 95(**), and 99 $\left.*^{* *}\right)$ percent. \\
\hline
\end{tabular}

Figure 1 below gives the distribution of log real weekly wages before and after treatment in the treatment states and in control states both pre and post treatment. We can clearly see a rightward shift in the distribution of log real wages in the case of treatment states, which is larger than the shift in distribution of the control group distribution.

We conduct a similar analysis for our second outcome variable, which is a measure of unemployment. We find no statistically significant impact of the minimum wage legislation on the unemployment measure. This implies that the states where minimum wages were instituted, the employers did not reduce

17 The number of clusters are 33

18 We create dummies 10 big metros or cities of India namely Mumbai Delhi Kolkata Chennai Bangalore Hyderabad Ahmedabad Pune Surat and Jaipur and include it as additional controls in our MDID regressions along with interaction controls. The result tables can be presented on request 
Figure 1: Kernel Density Plot of Log Real Wage Distribution in Treatment and Control States

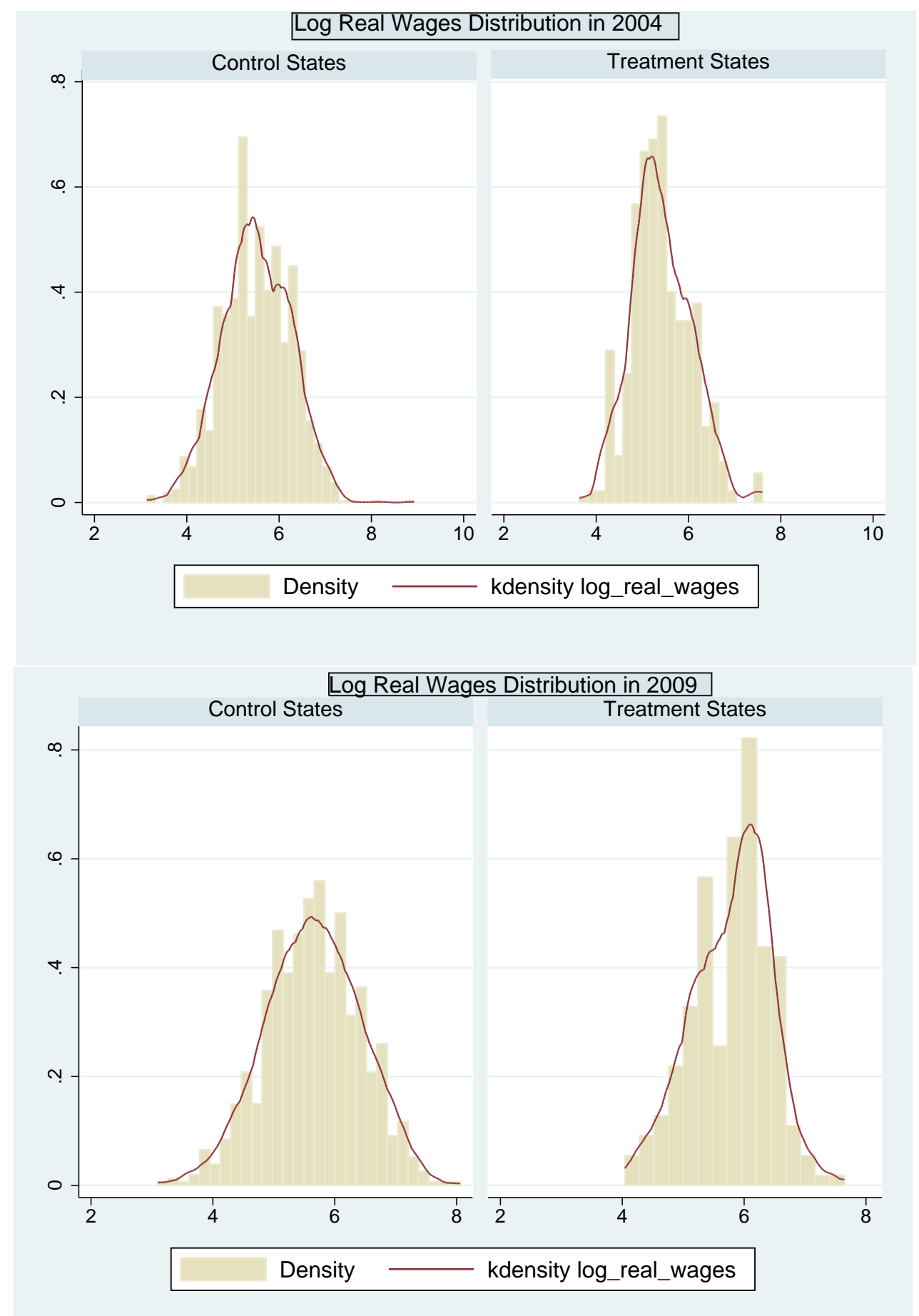

the employment opportunities to workers. While this is good for workers, it could also imply that employers did not bother to increase the wages offered to workers in response to the minimum wage legislation and did not strictly comply with the legislation. This open up the question of actual implementation and enforcement of this legislation, this is further explored in the later sections of the paper. 


\subsection{Aggregate Results : Long-Run Impacts}

We have a second survey round corresponding to post-treatment period for four treatment states, whose short-run analysis we presented in the previous section. This enables us to study whether the positive impact of the legislation persisted in these states in the long-run. We repeat the analyses conducted in the short-run for this long-run analyses, using the 2012 survey data as the post-treatment year. Table 5 , provide the normal diff-in-diff and e-balance estimations of the long-run impact of the minimum wage legislation. We find that the treatment impact has reduced in magnitude and also has become statistically insignificant. We also use the matching with diff-in-diff and arrive at the exact same conclusions in terms of the magnitide of impact and its statistical significance, as shown in table 7. Our results suggests that the impact of minimum wage legislation in these four treatment states seems to have worn off by 2012 . We also run long run DID , ebalance and MDID estimations by including a) state dummies separately ,b) with city dummies separately,c)with state dummies and interaction terms and d) with city dummy and interaction terms.For all these specifications we find an insignificant impact of the minimum wage legislation on the real weekly wages.The magnitude of the impact is also very similar ${ }^{19}$ to the previous long run results in Table 5,6 and 7. This result could be attributed to the lack of proper enforcement mechanism of this minimum wage legislation. There could have been partial compliance to the legislation immediately following its introduction. However, with passage of time domestic households realise that this legislation is not enforced and that there is no effective monitoring mechanism of its implementation at the domestic household level. Hence, there seems to have been very little incentive for the private households to offer higher wages to domestic sector workers under these circumstances. Ground-level situational analyses provided in Neetha [2013] and other studies highlight this lack of proper enforcement as the most significant explanation for the lack of impact of this legislation. To verify this causal mechanism, we conduct a difference-in-difference estimation of the impact of treatment on real wages for the period of 2009 and 2012. ${ }^{20}$ We clearly see a negative and statistically significant impact of treatment on real wages durign this period. The magnitude of reversal of real wages is almost equivalent to the increase in real wages that we observed from 2004 to 2012 in these treatment states. This suggests that whatever postitve impact that we observed over 2004-2009 was reversed by 2012, leading to an overall insgnificant impact of the treatment.

We repeat the long-run analysis with unemployment measure as the outcome variable in table 6 and 7. Similar to the short-run case, we find no evidence of impact on the unemployment measure. Hence, it rules out the possibility that the lack of significant impact on real wages in the long-run was due to changes in employment options for workers. For instance, if workers had experienced higher unemployment rates following the introduction of the minimum wage legislation, it would have led them to negotiate for lower wages with their employers, which in turn would have reduced the impact of

19 Tables not included in the paper.It can provided on request by the authors

20 The results are added to the appendix table 18 . 
Table 5: Long Run: DiD and E-balance estimations

\begin{tabular}{lcccc}
\hline Outcome Variable : & Log Real Wages & Log Real Wages & Log Real Wages & Log Real Wages \\
Estimation : & DiD & DiD & E-balance \& DiD & E-balance \& DiD \\
Post & $0.28^{* * *}$ & $0.27 * * *$ & $0.30^{* * *}$ & $0.27^{* * *}$ \\
& 0.05 & 0.04 & 0.05 & .05 \\
Treatment states & -0.08 & -0.11 & -0.10 & $-0.10^{* * *}$ \\
& 0.05 & 0.04 & 0.06 & .04 \\
Post*treatment states & 0.08 & 0.12 & 0.09 & 0.12 \\
& 0.10 & 0.08 & 0.09 & .08 \\
Controls & Yes & Yes & Yes & Yes \\
Interactions & No & Yes & No & Yes \\
N & 1723 & 1723 & 1723 & 1723 \\
R2 & 0.272 & 0.335 & 0.343 & 0.359 \\
\hline Standard errors clustered at state level in paranthesis & \multicolumn{3}{c}{} \\
$*, * * * * *$ indicate significance at 1,5 and $10 \%$ significance levels & \\
Control group refers to domestic workers in the non-treated states (excluding Kerala) \\
\hline
\end{tabular}

Table 6: Long Run: DiD and E-balance estimations

\begin{tabular}{lcccc}
\hline Outcome Variable : & Unemployment & Unemployment & Unemployment & Unemployment \\
Estimation : & DiD & DiD & E-balance \& DiD & E-balance \& DiD \\
Post & -0.17 & $-0.19^{* *}$ & $-0.23^{*}$ & $-0.36^{*}$ \\
& 0.10 & 0.11 & 0.13 & .14 \\
Treatment states & -0.05 & -0.04 & -0.06 & -0.09 \\
& 0.22 & 0.24 & 0.26 & .18 \\
Post*treatment states & -0.18 & -0.17 & -0.16 & -0.01 \\
& 0.17 & 0.21 & 0.27 & .23 \\
Controls & Yes & Yes & Yes & Yes \\
Interactions & No & Yes & No & 1622 \\
N & 1622 & 1622 & 1622 & 0.061 \\
R2 & 0.01 & 0.04 & 0.026 & \\
\hline Standard errors clustered at State level in paranthesis & & \\
$*, * * * * *$ indicate significance at 1,5 and $10 \%$ significance levels & \\
Control group refers to domestic workers in the non-treated states (excluding Kerala) \\
\hline
\end{tabular}

Table 7: Long Run:MDID Estimation Results

\begin{tabular}{crrrrrrl}
\hline \multicolumn{1}{c}{ Base Line (BL) } & \multicolumn{1}{c}{ Follow Up (FU) } & DiD \\
\hline Outcome Variable & Control & Treated & Diff(BL) & Control & Treated & Diff(FU) \\
Log real wages & 5.43 & 5.35 & -0.07 & 5.8 & 5.8 & -0.005 & 0.07 \\
& 0.04 & 0.05 & 0.07 & 0.08 & 0.05 & 0.09 & 0.12 \\
Months Unemployed & 0.56 & 0.509 & -0.05 & 0.43 & 0.15 & $-0.28^{* *}$ & -0.22 \\
& 0.13 & 0.19 & 0.23 & 0.12 & 0.04 & 0.13 & 0.2 \\
\hline Notes : Clustered standard errors reported in paranthesis. \\
Number of Clusters is 33 \\
DiD indicates the difference in difference estimate of the outcome variable. \\
Significant at 90 $(*), 95(* *)$, and 99 $(* * *)$ percent. \\
Control group refers to domestic workers in the non-treated states (excluding Kerala) \\
Matching is done within control and treated groups separately between post and pre treatment periods \\
\hline
\end{tabular}


minimum wage legislation on wages. However, employment opportunities seems not to have responded to the minimum wage legislation in both short-run and in long-run.

\subsection{Intensity of Treatment}

As explained in the earlier section, the minimum wages set by the various treatment states differed widely in terms of hourly rates, the method of calculation and the tasks included. Naturally, the difference between the pre-existing wages and the stipulated minimum wages, which defines the treatment intensity, also differed across these states. In this section we further analyse the impact of treatment intensity on our outcome variables.

In the minimum wage literature, the treatment intensity is most commonly quantified in terms of wage gap (WG), which is the difference between the minimum wages and the median wages in the pre-treatment period.

$$
W G_{s}=\log \left(\text { Minimumwage }_{s}\right)-\log \left({\text { Median } \left.\left(\text { wage }_{s, 2004}\right)\right)}\right.
$$

The median weekly wages for treatment states appear to be substantially lower than the instituted minimum wage rates. ${ }^{21}$

We adapt the difference-in-difference methodology described in earlier sections to take into account the impact of wage gap on the outcome variables using the following empirical model.

$$
y_{i s t}=\alpha_{0}+\alpha_{1} * \text { Post }_{t}+\alpha_{2} * W G_{s t}+\alpha_{3} * W G_{s t} * \text { Post }_{t}+\gamma * X_{i s t}+\epsilon
$$

Similar to the earlier equations ( 1 and 2), $\alpha_{3}$ gives us the difference-in-difference estimate of the impact of treatment intensity on our outcome variable. If $\alpha_{3}$ is positive and significant it implies that the states with higher treatment intensity (WG) registered higher increase in the outcome variable.While, $\alpha_{1}$ measures any generic shock on the outcome varable in the post-treatment period and $\alpha_{2}$ measures the average difference in outcome variable for the treatment states across periods.

Table 8 and 9 gives the estimations of the above empirical model both using normal difference-indifference and entropy balancing in the short-run and long-run respectively. We find that the intensity of treatment led to positive and statistically significant increase in log real wages in treatment states in the short-run. Higher the wage gap in treatment states higher was the increase in real wages. But this impact seems to attenuate in the long-run.This results holds with model specification including all covariates and their interactions as well. Similar to the earlier case, there seems to be no impact on the unemployment measure. ${ }^{22}$. However an important point to note is that minimum wages in each of the four treatment states have been updated since their respective state governments issued notification for

\footnotetext{
21 We calculated the weekly minimum wages using 8 hours work per day and 7 work days per week. To construct wage gap, the median weekly wages of each state for the pre-treatment year of 2004 were used.

22 The regression results for the case of unemployment is omitted here
} 
Table 8: Short Run : Intensity of Treatment

\begin{tabular}{lcccc}
\hline Outcome Variable : & Log Real Wages & Log Real Wages & Log Real Wages & Log Real Wages \\
Estimation : & DiD & DiD & E-balance \& DiD & E-balance \& DiD \\
Post & -0.02 & -0.04 & -0.0002 & 0.004 \\
& 0.05 & 0.05 & 0.04 & 0.05 \\
Wage Gap & $-0.05^{*}$ & $-0.06^{* *}$ & $-0.06^{* *}$ & $-0.06^{* *}$ \\
& 0.03 & 0.02 & 0.03 & 0.02 \\
Post*Wage Gap & $0.16^{* *}$ & $0.16^{* *}$ & $0.16^{* * *}$ & $0.14^{* * *}$ \\
& 0.06 & 0.06 & 0.04 & 0.04 \\
Controls & Yes & Yes & Yes & Yes \\
Interactions & No & Yes & No & Yes \\
N & 1764 & 1764 & 1764 & 1763 \\
R2 & 0.243 & 0.302 & 0.283 & 0.356 \\
\hline Standard errors clustered at state level in paranthesis & \\
$* * * * * *$ indicate significance at 1,5 and $10 \%$ significance levels & \\
Control group refers to domestic workers in the non-treated states (excluding Kerala) \\
\hline
\end{tabular}

Table 9: Long Run : Intensity of Treatment

\begin{tabular}{lcccc}
\hline Outcome Variable : & Log Real Wages & Log Real Wages & Log Real Wages & Log Real Wages \\
Estimation : & DiD & DiD & E-balance \& DiD & E-balance \& DiD \\
Post & $.28^{* * *}$ & $.26^{* * * *}$ & $.31^{* * * *}$ & $.27^{* * * *}$ \\
& .04 & 0.03 & .05 & 0.05 \\
Wage Gap & $-0.05^{* *}$ & $-.06^{* *}$ & $-.05^{* *}$ & $-0.06^{* *}$ \\
& 0.02 & 0.02 & 0.03 & 0.02 \\
Post*Wage Gap & 0.05 & $0.07^{* *}$ & 0.05 & .08 \\
& 0.04 & 0.04 & 0.05 & 0.05 \\
Controls & Yes & Yes & Yes & Yes \\
Interactions & No & Yes & No & Yes \\
$\mathrm{N}$ & 1723 & 1723 & 1723 & 1723 \\
R2 & 0.272 & 0.335 & 0.305 & 0.359 \\
\hline Standard errors clustered at state level in paranthesis & \multicolumn{3}{c}{} \\
$* * * * * *$ indicate significance at 1,5 and $10 \%$ significance levels & \\
Control group refers to domestic workers in the non-treated states (excluding Kerala) \\
\hline
\end{tabular}


minimum wages to domestic workers for the first time. In the preceding analysis we used the minimum wages as updated until September 2012. While the use of the 2012 minimum wages is relevant for the long run intensity of treatment (in Table 9), we re-run our short run intensity of treatment by creating wage gap variable for each of the treatment states with minimum wages notified until the year $2010^{23}$.We also run specifications by including state dummies and interactions (both individually and together). The short run impact remains positive and significant as before.However the magnitude seems to have increased slightly from an earlier range of 0.14 to 0.16 (which is the coefficient $\alpha_{3}$ ) to a range of 0.175 to 0.21 .This indicates that wage gap was much higher if we use the 2010 minimum wages. Furthermore using the 2010 updated minimum wages the long run intensity of treatment remains insignificant.

\subsection{Impact at the Extensive Margin}

In this sub-section we try to identify if the minimum wage legislation had any impact at the extensive margin. The question is did the minimum wage legislation increase the probability of being employed as a domestic worker in these treatment states ? To study this impact at the extensive margin, we develop a dummy variable that indicates if the worker is a domestic sector worker or not. As a comparator group, we restrict our sample to all categories of unskilled job categories that could provide job alternatives to potential domestic worker. We use the dummy variable as the dependent variable and use a linear probability model, within the normal difference-in-difference and entropy balancing frameworks described earlier. Hence, the only difference here is that the outcome variable is a dummy variable indicating employment status in domestic work. We conduct our analysis for both short-run and long-run time frame described above. Table 10 and 11 provide the results. It seems that there was a secular decline in the overall probability of being employed as a domestic worker in India since 2004, denoted by the negative and significant coefficient of the Post variable. This could be because of opening up of other employment opportunities in the urban centres. However, our treatment effect is statistically insignificant implying that the minimum wage legislation did not affect the probability of being employed as a domestic worker in these treatment states. Hence, there seems to be no evidence of significant treatment impact at the extensive margin. Considering that the legislation had only a limited magnitude short-term impact on wages in treatment states, this does not come as a surprise. In South Africa, Dinkelman and Ranchhod [2012] find that despite strong positive impact on wages of domestic sector workers, there was no evidence of any impact at the extensive margin following the minimum wage legislation. Our conclusions seem to resonate with the South African minimum wage legislation impact in this respect. We also conduct an extension of this analysis to determine if the treatment did have any impact on the probability of being employed in some proxy sectors that could provide alternative employment opportunities to workers that engage in domestic sector. We conduct similar extensive margin analysis on the probability

\footnotetext{
23 the 2010 minimum wages were recovered from the Labour Bureau of India
} 
of being employed as hotel or restaurant workers and cleaners. We find no treatment spill over to these proxy sectors at the extensive margin. The results of these extensive margin analysis for placebo sectors are included in appendix tables 14 and 15.

Table 10: Short Run : Treatment Impact at the Extensive Margin

\begin{tabular}{lcccc}
\hline \multicolumn{5}{c}{ Outcome Variable : Probability of Employment as Domestic Worker } \\
Estimation : & DiD & DiD & E-balance \& DiD & E-balance \& DiD \\
Post & $-.003^{* * *}$ & $-.002^{* * *}$ & $-.003^{* * *}$ & $-.003^{* * *}$ \\
& .0006 & .0005 & .0003 & .0004 \\
Treatment states & -.002 & -.002 & -.001 & $-.002^{* *}$ \\
& .002 & .002 & .0006 & .0007 \\
Post*treatment states & .0005 & .0004 & .00009 & .0002 \\
& .001 & .001 & .0008 & .0008 \\
Controls & Yes & Yes & Yes & Yes \\
Interactions & No & Yes & No & Yes \\
$\mathrm{N}$ & 261250 & 261250 & 261250 & 261250 \\
R2 & 0.01 & 0.02 & 0.01 & 0.01 \\
\hline Standard errors clustered at state level in paranthesis \\
$* * * * * *$ indicate significance at 1,5 and 10 \% significance levels \\
Control group refers to domestic workers in the non-treated states (excluding Kerala) \\
\hline \multicolumn{5}{l}{}
\end{tabular}

Table 11: Long Run : Treatment Impact at the Extensive Margin

\begin{tabular}{|c|c|c|c|c|}
\hline \multicolumn{5}{|c|}{ Outcome Variable : Probability of Employment as Domestic Worker } \\
\hline Estimation : & DiD & DiD & E-balance \& DiD & E-balance \& DiD \\
\hline \multirow[t]{2}{*}{ Post } & $-.004 * * *$ & $-.003 * * *$ & $-.004 * * *$ & $-.003 * * *$ \\
\hline & .0007 & .0008 & .0003 & .0003 \\
\hline \multirow[t]{2}{*}{ Treatment states } & .0003 & -.0003 & .0009 & -.00003 \\
\hline & 0.003 & .002 & .0007 & .0007 \\
\hline \multirow[t]{2}{*}{ Post*treatment states } & -.0007 & -.0005 & -.0007 & -.0004 \\
\hline & .001 & .001 & .0009 & .0009 \\
\hline Controls & Yes & Yes & Yes & Yes \\
\hline Interactions & No & Yes & No & Yes \\
\hline $\mathrm{N}$ & 360699 & 360699 & 360699 & 360699 \\
\hline R2 & 0.01 & 0.03 & 0.01 & 0.03 \\
\hline \multicolumn{5}{|c|}{ Standard errors clustered at state level in paranthesis } \\
\hline
\end{tabular}

\section{Robustness Checks}

As explained in the section on estimation methodology, the difference-in-difference approach strongly relies on the assumption of parallel trends, even when we combine the same with matching methodology. Since we have two survey rounds prior to treatment, pertaining to 1999 and 2004 respectively, we test the assumption of parallel trends.The methodology of testing for parallel trends is straight forward. We assume that year 2004 is the post-treatment phase and 1999 as the pre-treatment phase. We estimate the same difference-in-difference equation we outlined earlier, namely 


$$
y_{i s t}=\alpha_{0}+\alpha_{1} * \text { Post }_{t}+\alpha_{2} * \text { treatmentstates }_{\text {st }}+\alpha_{3} * \text { treatmentstates }_{\text {st }} * \text { Post }_{t}+\gamma * X_{\text {ist }}+\epsilon
$$

In order for parallel trends to hold, our estimate of $\alpha_{3}$ should not be statistically significant. This implies that treatment and control groups had similar increase in outcome variables and moved parallel in normal years without minimum wage legislations. We check for parallel trends assumption using normal DiD, entropy balance and MDID approach using the two pre-treatment years. These estimations are inlcuded in the appendix tables 16 and 17. We find that parallel trends assumption holds for both real wages and unemployment measures. Figure 2 shows the trend of average real wages in the pretreatment period (i.e., 1999 and 2004) for both treated and control states which supports the parallel trend assumption $^{24}$. Furthermore in Figure 4 as seen in the appendix we graph the distribution of log real wages for control and treated states in 1999 and 2004 (which is our pre-treatment period). Eyeballing these graphs further suggests that trend in the distribution of log real wages in both the treatment and control is very similar. This in turn supports our previous conclusion that the parallel trends assumption holds. The parallel trends assumption also seems to hold for months unemployed seen in Figure 5 (and shown in the appendix).

Figure 2: Pretreatment Trend of Real Wages in Treatment and Control States

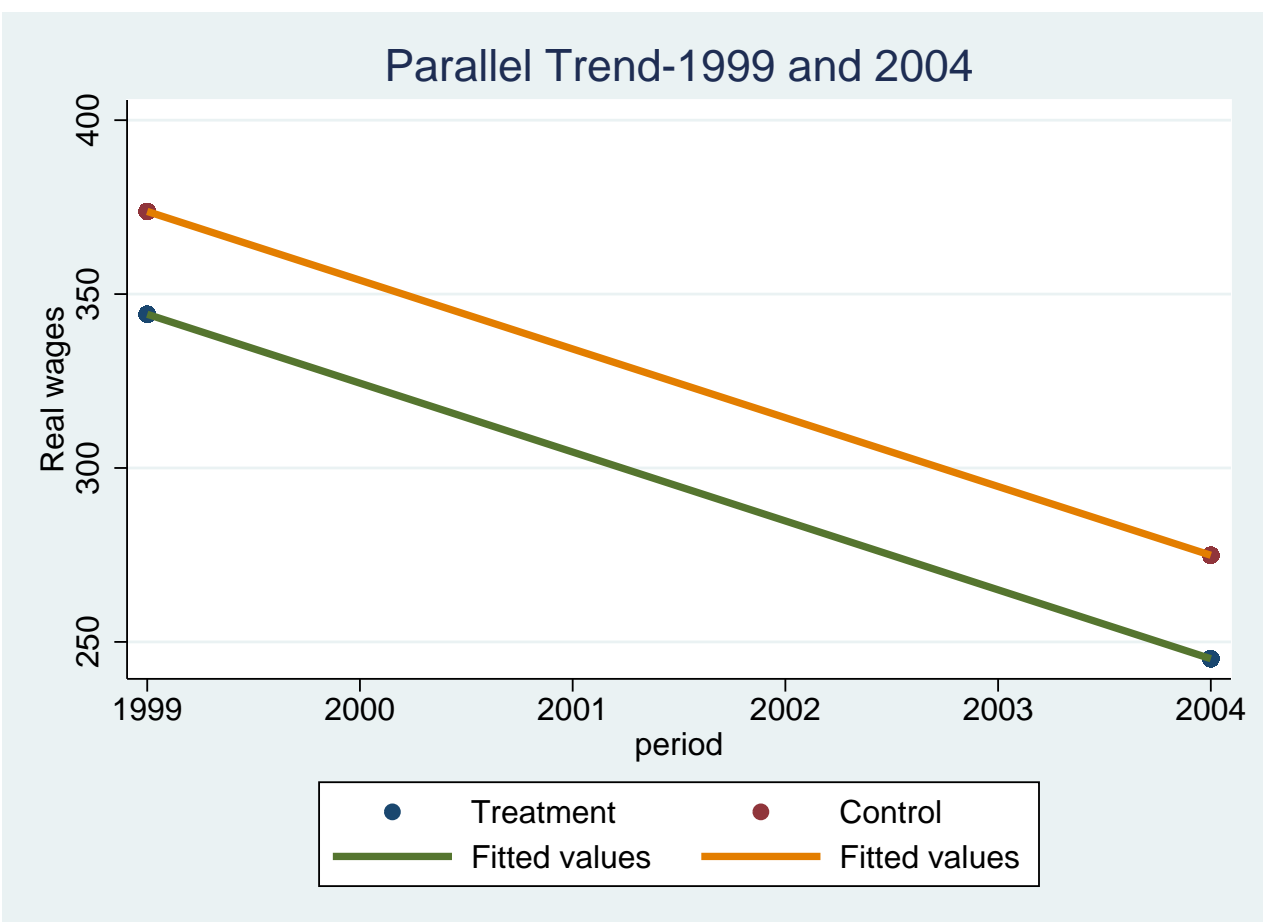

The second assumption that MDID relies on is that of common support, which translates to the fact there is adequate overlap in the characteristics of treated and control group units to find sufficient matches. We test this assumption for all our MDID estimations and we find that common support as-

\footnotetext{
24 The fitted varlues are estimated using a simple linear regression of real wages on time and an intercept
} 
sumption holds in terms of each of our covariates and their interactions for both our outcome variables.

In order to ensure that our results are not driven by any one particular state, we remove one treatment state at a time and re-run our analyses and we find that our results holds in all these specifications. In Karnataka the treatment took place in 2005, hence by the time we record the treatment impact in 2009, around four years have passed since the introduction of the legislation in Karnataka. While in other states the treatment impact is recorded within a much shorter time frame. When we remove Karnataka from our sample and re-run the short run analysis we find that treatment impact magnitude become stronger. Hence, the positive short-run impact on wages in Karnataka is already disappearing by 2009. ${ }^{25}$

We conduct further robustness check by running the exact difference-in-difference estimations used to derive our main results for a placebo sector. We selected workers in hotels and restaurants to be the placebo sector as their tasks and even work timings are comparable to that of domestic workers. If our main results hold, the difference-in-difference analysis of the outcome variables (wages and unemployment) should not show any significant results for this placebo sector. We conduct the normal diff-in-diff, ebalance and matching analysis and find that there is no statistically significant treatment effect in this placebo sector. The results of this robustness check is provided in table 12 and 13 in the appendix. This implies that the treatment effect was not capturing any macro-level shock that affected all similar sectors of these treatment states during the post-treatment period. This imparts further confidence in our identification strategy's ability to isolate the impact of the treatment on domestic sector workers.

In order to develop a more comparable control group, we further restrict our control groups to untreated states that share borders with treatment states and then re-run the analysis. The results of this robustness check provided in table 19 and 20 in the appendix clearly show that after restricting the control group to the untreated border states, we see a significant treatment effect but with similar signs and magnitude on log real wages in the short run and no significant effect on in the long run.The increase in real wages in the short run is around Rs 1.5 per week which is similar to the increase in our main results.

Domestic work sector in India is dominated by female workers, so we conducted a sub-sample analysis for female workers. Our results remain similar in magnitude and in significance level for this sub-group 26 .

Unemployment for long duration could indicate lower abilities which might translate to lower earnings potential. In order to purge our analysis from such impacts, we removed the workers who were unemployed for more than 6 months in the past year from our sample and repeated the analysis. We find that our results holds even after removing these outliers ${ }^{27}$.

Implementation capacity of states could be different, which could hamper the implementation of any law. We looked at the NREGS implementation performance reports of the four treatment states. Andhra

\footnotetext{
25 For brevity, results of these robustness checks are not included here and would be made available upon request.

26 We could not conduct a similar sub-group analysis for male workers due to insufficient observations in some states. For brevity, results of these robustness checks are not included here and would be made available upon request.

27 The results can be made available on request
} 
Pradesh and Rajasthan emerge as top performers in terms of NREGS implementation, with Karnataka and Bihar trailing behind [Breman and Varinder, 2012]. So we clubbed together the two top-performers and repeated the analysis exclusively for these two treatment states. We found that our results did not vary from the main findings, suggesting that the minimum wage law implementation did not vary significantly in these two states ${ }^{28}$.

Though we use individual level data, our treatment takes place at the state level. The number of states is rather small. Under such circumstance, there is a possibility that our standard errors are potentially biased. In all our previous regressions we control for this group effect by clustering the standard errors at the state level. However, the consistency of standard errors are also questionable with the limited number of groups. We therefore conduct robustness checks of our main results using the Donald and Lang (2007) procedure. This is a two step procedure, in the first step we regress outcome variables on all individual level variables, dummies for each states (State), the Post variable, and the Post and State interaction term. The coefficients from the province dummies are then regressed on Post, treatment states, and treatment states and Post variable interaction in the second stage to obtain the difference-in-difference estimators explained earlier in the paper. Such an estimation process renders more precise estimation of standard errors. Our key results and conclusions hold even after controlling for these group effects ${ }^{29}$.

\section{Discussions and Implications for Future Research}

The main conclusion derived from the above analysis is that minimum wage legislation for domestic sector workers seems to have had impact in terms of real wages at least in the short-run (by 2009), while no impact was detected in the long-run (by 2012).

The estimated impact on log real wages is of the magnitude of 0.3, which translates to Rs 1.3 (in 2004 prices) . This implies that real wages increased on average in excess of Rs 1.2 in treatment states compared to the control group states. This impact of minimum wage legislation is rather limited, considering that the mean weekly real wages stood at Rs 460 in 2009. Even this small positive impact of the legislation seems to disappear by 2012, which we attribute to lack of monitoring and enforcement mechanism which accompanied the legislation. There was very little incentive for the domestic household to adhere to the minimum wage legislation.

This throws light on the question of how these minimum wages stood in comparison to the wage levels that existed in these states before the implementation of minimum wage legislation. If the minimum wages instituted by these states were comparable to the existing wages in the sector, then even the full enforcement of a minimum wage legislation need not make any significant impact in terms of magnitude. In our analyses of treatment intensity, we attempted to answer this question. We found out that the pre-

28 The results can be made available on request

29 The results can be made available on request 
existing minimum wages were considerably lower than that of the introduced minimum wages in the treatment states. Hence, if the minimum wage legislation was implemented properly, we would have observed greater impact on the outcome variable of real wages. Further, the median weekly wages in post-treatment period in treatment states were considerably lower compared to the stipulated minimum wages.

Hence, from the results from our analyses on the magnitude of impact of the legislation, we can easily infer that the implementation and enforcement of this legislation was met with limited success.A theoretical explanation can be found in Basu et al. [2010] which shows that turning a blind eye to a minimum wage legislation by the very same government which passed it can be an equilibrium phenomenon with ex post credibility in a model of minimum wage policy with imperfect competition,imperfect enforcement and imperfect commitment.The result indicates that since credible enforcement mostly likely requires costly ex post transfer of income from employers to workers, a government concerned only with pareto efficiency but not with distribution is unable to credibly elicit efficiency improvements via a minimum wage reform.This theoretical conclusion is in line with our results. Our explanation, supported by the theoretical model in Basu et al. [2010], focuses on the failure in the enforcement of the law. Interestingly, congruent to these theoretical implication, in Karnataka and Andhra Pradesh, the minimum wage notification for domestic sector workers came with the explicit guideline that employers are exempted from maintaining records of employment [Neetha, 2013]. This could suggest that the ruling parties were trying to pacify the employers of domestic workers by assuring them that there won't be any monitoring and enforcement mechanism through labor inspections. At the very least, following the NREGS scheme which was implemented since 2005 in India, each employer should be required by law to maintain a muster roll where hours of work and wages paid for domestic workers are recorded regularly.

Our results are not at all startling looking at the implementation mechanism that accompanied these legislation. In Bihar and Rajasthan the legislation was restricted to a mere official notification by the government, while in Karnataka and Andhra Pradesh even though the legislation was preceded by several ground level movements and unionisation, complaint redressal and monitoring mechanisms were virtually non-existent. As a result, the magnitude of impact on real wages is rather limited and the impact seems to have waned off completely by 2012 .

These results open up new insights on the minimum wage legislations pertaining to domestic workers. There has been an increasing demand from various international organizations, national level movements and NGOs to institute minimum wages for domestic workers across all states in India. Our study finds that such legislations alone cannot make much difference to the lives of domestic workers. A strong, transparent and efficient monitoring mechanism accompanying such legislations could go a long way to enforce the same. From the experience of Karnataka and Andhra Pradesh we can infer that strong workers unions can be a first step in terms of demanding such legislations. This could also spread awareness about the legislation amongst the domestic workers. An All India Domestic Workers Union was formed in 2012. However, such unions alone cannot ensure enforcement as the median wages of Karnataka and Andhra 
Pradesh after the institution of minimum wage legislation were still quite lower than their stipulated minimum wages. As seen in Kerala (not included in our analysis) the role of the domestic wing of Self Employed Women's Association (SEWA) was key in improving the bargaining position of domesticworkers when it came to decent wages, working conditions and social security as compared to other states where the law is implemented. Kerala ${ }^{30}$, especially its urban areas, has been an exception under the leadership of SEWA where there was an informal norm of minimum wage standards for domestic workers as early as in 1989 [George, 2013]. ${ }^{31}$.

The majority of domestic workers operate on an informal basis mostly without a work contract or any kind of formal agreement regarding number of holidays per year. Sengupta and Sen [2013] point to the fact that the minimum wage law protect the employers interests compared to that of the domestic workers as the employers do not have to maintain registers on wages given nor create contracts with the domestic workers. This certainly complicates the monitoring and enforcement mechanism in this sector. Perhaps minimum wage legislations should also make it compulsory to issue formal contracts to domestic workers. Stronger formalisation efforts need to accompany these minimum wage legislation to increase the probability of enforcement. Formalizing the overall rights of the domestic workers beyond just the minimum wage could be useful. This was the approach taken in Brazil, where minimum wage legislation for domestic workers was followed up by efforts to increase formalisation of the sectors. This was started by guaranteeing fundamental labor rights enjoyed by workers in other sectors to domestic workers, also registration of labor cards of domestic workers was made mandatory. Subsequent to these efforts in Brazil, between 2001 and 2009 the number of formalised domestic workers increased by 30\% in Brazil [Gomes and Puig, 2013]. In India, there were no noticeable efforts to formalise the domestic worker sector after the minimum wage legislation.

Another possible intervention to increase enforcement of minimum wage legislation is through providing incentives for employers to comply with the legislation. Incentives in terms of tax credits are used in Belgium and France to increase compliance to regulations in domestic sector employment [D'souza, 2010]. India can learn from the success of the Universal Service Employment Cheque OR Cheque Emloi Service Universel (CESU) scheme in France. The main objective of this schemes is to a) combat undeclared work in domestic services and b) provide formal employment particularly for workers employed in informal jobs such as domestic cleaning,gardening etc. The twin objectives of the scheme is achieved by simplifying the process for hiring and paying domestic and temporary workers and by providing tax reductions to the employer. For example under the scheme the employer first registers with the local branch of the Agencies for the Collection of Social Security and Family Allowance Contributions (URSSAF) by completing an application at the bank or post office managing the employer account; after which the employers can purchase cheques from their local banks. By using these cheques to pay domestic workers

30 Kerala notified its official minimum wage for domestic workers only in 2010

31 SEWA registered itself as a national trade union in 2007 
at home as well as child care outside home (provided by any individual or organisation), the employer can avail an income tax reduction of 50 percent of the sum spent on purchasing the cheques, upto a maximum of Euro 1,830. Similar incentive mechanisms could be designed in India to support the minimum wage legislation.

Placement agencies that recruits workers from rural areas to be placed in urban households are emerging as key players in this largely informal domestic work sector. Regulating the work of these agencies by instituting strict guidelines on the need for maintaining records, formal contracts and ensuring guaranteed number of holidays per year for hired candidates could be another way of improving the effective implementation of the minimum wage legislation.

The Government of India has initiated a new universal identification scheme in terms of issuing biometric id cards (called Aadhar cards) that are attached to bank accounts of all citizens. Once this scheme is complete, the payment of domestic sector wages to the workers bank accounts could be made mandatory. Such bank transactions will provide a good documentation for wages paid and if combined with easier monitoring and complaint redressal mechansims, could perhaps ensure greater compliance to minimum wage legislations. It is obvious that we are still a long way from formalising this largely informal sector.

There are couple of points for future research. We mentioned earlier in this paper that one of the reasons why we restrict our analyses to the urban sample is because of the potential impact of NREGS on rural workers. It has been found that NREGS also had an impact on rural-urban migration. It needs to be studied whether the reduction of potential domestic workers arrival rate in urban areas affected our estimations of the impact of minimum wage legislation in any substantial manner. Since NREGS was an all India scheme which was expanded to all districts in India before our post-treatment periods, it is reasonable to assume that most urban areas would have felt the reduction in flow of rural migrants in a more or less uniform manner, hence, this should not impact our difference-in-difference estimations. This needs to be verified and confirmed through appropriate future research.

On a related note, the impact of minimum wage legislation on migration within India needs to be studied. Higher wages and assured minimum wages could trigger higher migration to an urban center, which might provide incentive for households to lower the offered wages to domestic workers. It needs to be researched if differing migration rates played any role in the gradual reduction of the impact from the minimum wage legislation in the long-run. But considering how small the magnitude of impact of minimum wage legislation was even in the short-run, it is quite unlikely that it triggered any significant changes in migration patterns.

Another pointer for future research is the impact of union membership of worker on wage bargaining. It could be the case that workers who were part of unions experienced much larger increase in wages following the introduction of minimum wage laws. Hence the exact impact of domestic workers' unions needs to be carefully explored and estimated.

We looked at the implication of the legislation only on two primary outcome variables, namely, wages 
and unemployment. The reason for restricting our analysis to these two outcome variables is because theoretically minimum wage legislation will have the strongest direct impact on these two dimensions. We did not look into the impact of the legislation on overall human development of workers ( such as their rights, consumption, the schooling outcomes of their children). This is because since we detected only very weak impact of the legislation on wages and unemployment, its highly unlikely that the legislation had any significant secondary impact in terms of any human development measures. However, such secondary impacts can be explored as part of future research.

\section{Conclusion}

In this paper, we conduct an impact evaluation of the minimum wage legislation for domestic workers in urban areas of four Indian states. We test the impact of the legislation at both intensive (real wages) and extensive (employment opportunity) margins in both short-run and in long-run. We find that the minimum wage legislation had positive and statistically significant impact on real wages in the short-run. This impact was itself very weak in magnitude. We also found similar impact in terms of the intensity of the treatment itself, measured by wage gap. Higher wage gap resulted in higher treatment impact in the short-run. However, all impact on real wages seems to disappear by 2012 in these four states. In the case of employment opportunities and the probability of being employed as a domestic worker, the legislation seems to have had no impact in both short and long run. From the ground-level situational analyses of these treatment states, we find that the legislation was not accompanied by any strong enforcement and monitoring mechanisms, which we attribute as the key factor driving our results. We provide several policy recommendations to increase the degree and extent of enforcement of this legislation. We also suggest avenues of future research to expand the nascent literature on minimum wage legislation for domestic sector workers.

\section{References}

Rita Almeida and Pedro Carneiro. Enforcement of labor regulation, informal labor, and firm performance. Policy research working papers, The World Bank, October 2005. URL http://hdl.handle.net/ $10986 / 8409$.

Rita Almeida and Pedro Carneiro. Inequality and Employment in a Dual Economy: Enforcement of Labor Regulation in Brazil. Number 3094 in IZA Discussion Paper. Bonn Germany, October 2007.

Rita Almeida and Pedro Carneiro. Enforcement of labor regulation and informality. CeMMAP working paper CWP29/11, Centre for Microdata Methods and Practice, Institute for Fiscal Studies, 2011. URL http://ideas.repec.org/p/ifs/cemmap/29-11.html. 
William Lester Arindrajit Dube and Michael Reich. Minimum wage effects across state borders:estimates using contiguous counties". The Review of Economics and Statistics, 92(4):945-964, 2010.

Nocola Cunningham Armacost. Domestic workers in india: A case for legislative action. Journal of the Indian Law Institute, , 36:53-63, 1994.

Orley Ashenfelter and Robert S. Smith. Compliance with the minimum wage law. Journal of Political Economy, 87(2):333-350, April 1979. ISSN 0022-3808. URL http://www.jstor.org/stable/ 1832090. ArticleType: research-article / Full publication date: Apr., 1979 / Copyright Âp 1979 The University of Chicago Press.

ArnabK. Basu, NancyH. Chau, and Ravi Kanbur. Turning a blind eye: Costly enforcement, credible commitment and minimum wage laws. Economic Journal, 120(543):244-269, 032010.

Linda A. Bell. The impact of minimum wages in mexico and colombia. Journal of Labor Economics, 15 (3):S102-35, 1997. URL http://ideas.repec.org/a/ucp/jlabec/v15y1997i3ps102-35. html.

P Besler and U Rani. Extending the coverage of minimum wages in india: Simulations from household data. Conditions of Work and Employment Series 26, ILO, Geneva, June 2010. URL http: //www . ilo.org/travail/whatwedo/publications/WCMS_145336/lang--en/index.htm.

Richard Blundell and Monica Costa Dias. Alternative approaches to evaluation in empirical microeconomics. Journal of Human Resources, 44(3):565-640, June 2009. ISSN 0022-166X, 1548-8004. URL http://jhr. uwpress.org/content/44/3/565.

J. Breman and J. Varinder. Implementation of nrega in india a national overview. Hivos Knowledge Programme Paper, (9), 2012.

D Card and A Krueger. A reanalysis of the effect of the new jersey minimum wage increase on the fast food industry with representative payroll data. Working Paper 6386, NBER, 1998.

David Card and Alan B. Krueger. Minimum wages and employment: A case study of the fast-food industry in new jersey and pennsylvania. The American Economic Review, 84(4):772-793, September 1994. ISSN 0002-8282. URL http://www. jstor.org/stable/2118030.

J.M. Ian Salas David Neumark and William Wascher. Revisiting the minimum wage-employment debate: Throwing out the baby with the bathwater? Working Paper 18681, NBER, 2013.

Taryn Dinkelman and Vimal Ranchhod. Evidence on the impact of minimum wage laws in an informal sector: Domestic workers in south africa. Journal of Development Economics, 99(1):27-45, September 2012. ISSN 0304-3878. doi: 10.1016/j.jdeveco.2011.12.006. URL http://www. sciencedirect. $\mathrm{com} / \mathrm{science/article/pii/s0304387811001210.}$ 
Asha D'souza. Moving towards decent work for domestic workers:an overview of the ilo's work. Working Paper 2010/2, ILO, 2010.

Arindrajit Dube, Suresh Naidu, and Michael Reich. The economic effects of a citywide minimum wage. ILRReview, 60(4), July 2007. URL http://digitalcommons.ilr.cornell.edu/ilrreview/ vol60/iss $4 / 4$.

Suneetha Eluri and Alok Singh. Unionizing domestic workers:case study of intuc-karnataka domestic workers congress. Ilo report, ILO, 2013.

Sonia George. Towards recognition through professionalisation. Economic and Political Weekly, 48(43):69-76, October 2013. URL http://www.epw.in/review-womens-studies/ towards-recognition-through-professionalisation.html. While discussing the existing scenario of domestic workers in Kerala, this paper explains the processes involved in building \&quot;recognition\&quot; for domestic workers through the professionalisation of their work. The process is explained through the history of the organisation of Self Employed Women\&\#39;s AssociationKerala and locating within it the personal experiences of workers and service takers. The institutional setting of SEWA was fundamental in creating spaces for negotiation in terms of work regularity, decent wages, safe work conditions and social security.

T. H. Gindling and Katherine Terrell. The effects of multiple minimum wages throughout the labor market: The case of costa rica. Labour Economics, 14(3):485-511, 2007. URL http://ideas . repec.org/a/eee/labeco/v14y2007i3p485-511.html.

Ana Gomes and Inmaculada Baviera Puig. Domestic work after labour law: The case of brazil and spain. In Labour Law Research Network Conference, June 13-15, 2013. Pompeu Fabra University, Barcelona, 2013.

Jens Hainmueller. Entropy balancing for causal effects: A multivariate reweighting method to produce balanced samples in observational studies. Political Analysis, 20(1):25-46, January 2012. ISSN 1047-1987, 1476-4989. doi: 10.1093/pan/mpr025. URL http://pan.oxfordjournals.org/ content/20/1/25.

James Heckman, Hidehiko Ichimura, Jeffrey Smith, and Petra Todd. Characterizing selection bias using experimental data. Econometrica, 66(5):1017-1098, September 1998. ISSN 0012-9682. doi: 10. 2307/2999630. URL http://www.jstor.org/stable/2999630. ArticleType: research-article / Full publication date: Sep., 1998 / Copyright Âl 1998 The Econometric Society.

James J. Heckman, Hidehiko Ichimura, and Petra E. Todd. Matching as an econometric evaluation estimator: Evidence from evaluating a job training programme. The Review of Economic Studies, 64(4): 605-654, October 1997. ISSN 0034-6527. doi: 10.2307/2971733. URL http://www. jstor.org/ 
stable/2971733. ArticleType: research-article / Issue Title: Special Issue: Evaluation of Training and Other Social Programmes / Full publication date: Oct., 1997 / Copyright ÂP 1997 The Review of Economic Studies, Ltd.

K Lang and K Shulamit. The effect of minimum wage laws on the distribution of employment:theory and evidence. Journal of public economics, 69:67-82, 1998.

J. Peter Mattila. The effect of extending minimum wages to cover household maids. The Journal of Human Resources, 8(3):365-382, July 1973. ISSN 0022-166X. doi: 10.2307/144709. URL http: //www. jstor.org/stable/144709. ArticleType: research-article / Full publication date: Summer, 1973 / Copyright ÂP 1973 The Board of Regents of the University of Wisconsin System.

Dwayne Benjamin Michael Baker and Shuchita Stanger. The highs and lows of minimum wage effect:a time series cross section study of the canadian law. Journal of Labour Economics, 17(2):318-350, 1999.

N Neetha. Contours of domestic service: Characteristics, work relations and regulation. The Indian Journal of Labour Economic, 52, 2009.

N Neetha. Paid domestic work. Economic and Political Weekly, 48(43):35-38, October 2013. URL http: //www.epw.in/review-womens-studies/paid-domestic-work.html.

D Neumark and W Wascher. The effect of new jersey's minimum wage increase on fast food employment:a reevaluation using payroll records. Working Paper 5224, NBER, 1995a.

D Neumark and W Wascher. The effects of minimum wages on teenage employment and enrollment: Evidence from matched cps surveys. Working Paper 5092, NBER, 1995b.

David Neumark and William Wascher. Employment effects of minimum and subminimum wages: Panel data on state minimum wage laws. Industrial and Labor Relations Review, 46(1):55-81, October 1992. ISSN 0019-7939. doi: 10.2307/2524738. URL http://www. jstor.org/stable/2524738. ArticleType: research-article / Full publication date: Oct., 1992 / Copyright ÂP 1992 Cornell University, School of Industrial \& Labor Relations.

Lucas Ronconi. Enforcement and compliance with labor regulations. ILRReview, 63(4), April 2008. URL http://digitalcommons.ilr.cornell.edu/ilrreview/vol63/iss4/9.

Kamala Sankaran. Domestic work, unpaid work and wage rates. Economic and Political Weekly, 48(43):85-89, October 2013. URL http://www.epw.in/review-womens-studies/ domestic-work-unpaid-work-and-wage-rates.html.

Nilanjana Sengupta and Samita Sen. Bargaining over wages. Economic and Political Weekly, 48(43):55-62, October 2013. URL http://www.epw.in/review-womens-studies/ bargaining-over-wages.html. 
Vidhya Soundararajan. Minimum wages and enforcement in india inverted u-shaped employment effects.

In 8th IZA/World Bank Conference on Employment and Development, Deutsche Post DHL Convention

Center, Bonn, 2013.

\section{Appendix}

Table 12: Short Run : Impact on Real Wages of Placebo Sector

\begin{tabular}{lcccc}
\hline \hline Outcome Variable : & Log Real Wages & Log Real Wages & Log Real Wages & Log Real Wages \\
Estimation : & DiD & DiD & E-balance \& DiD & E-balance \& DiD \\
Post & -0.013 & -0.02 & -0.07 & .01 \\
& 0.04 & 0.04 & 0.06 & .06 \\
Treatment states & 0.03 & $0.11^{* *}$ & -.019 & $0.12^{* *}$ \\
& 0.05 & 0.05 & 0.09 & .06 \\
Post*treatment states & 0.10 & 0.014 & 0.15 & 0.006 \\
& 0.18 & 0.13 & 0.13 & .10 \\
Controls & Yes & Yes & Yes & Yes \\
Interactions & No & Yes & No & 767 \\
$\mathrm{~N}$ & 767 & 767 & 767 & 0.488 \\
R2 & 0.3281 & 0.454 & 0.332 & \\
\hline Standard errors clustered at State level in paranthesis & \\
$* * * * * *$ indicate significance at 1,5 and $10 \%$ significance levels & \\
Control group refers to placebo sector workers in the non-treated states (excluding Kerala) \\
\hline
\end{tabular}

Table 13: Long Run : Impact on Real Wages of Placebo Sector

\begin{tabular}{lcccc}
\hline Outcome Variable : & Log Real Wages & Log Real Wages & Log Real Wages & Log Real Wages \\
Estimation : & DiD & DiD & E-balance \& DiD & E-balance \& DiD \\
Post & $.30^{*}$ & $.29^{*}$ & $.46^{* * *}$ & $.47^{* * * *}$ \\
& 0.15 & 0.16 & 0.13 & .12 \\
Treatment states & 0.03 & $0.10^{*}$ & .04 & 0.09 \\
& 0.05 & 0.05 & 0.07 & .06 \\
Post*treatment states & 0.14 & 0.12 & -.05 & -.08 \\
& 0.16 & 0.18 & 0.17 & .18 \\
Controls & Yes & Yes & Yes & Yes \\
Interactions & No & Yes & No & Yes \\
N & 513 & 513 & 513 & 513 \\
R2 & 0.402 & 0.589 & 0.370 & 0.566 \\
\hline Standard errors clustered at State level in paranthesis & \\
$* * * * * *$ indicate significance at 1,5 and $10 \%$ significance levels & \\
Control group refers to placebo sector workers in the non-treated states (excluding Kerala) \\
\hline
\end{tabular}


Table 14: Short Run : Treatment Impact at the Extensive Margin in Placebo Sector

\begin{tabular}{|c|c|c|c|c|}
\hline \multicolumn{5}{|c|}{ Outcome Variable : Probability of Employment as Domestic Worker } \\
\hline Estimation : & $\mathrm{DiD}$ & DiD & E-balance \& DiD & E-balance \& DiD \\
\hline \multirow[t]{2}{*}{ Post } & .001 & .001 & .0002 & -.0006 \\
\hline & .004 & .004 & .002 & .002 \\
\hline \multirow[t]{2}{*}{ Treatment states } & .007 & .007 & $.008 * *$ & $.007 *$ \\
\hline & .006 & .006 & .0004 & .004 \\
\hline \multirow[t]{2}{*}{ Post*treatment states } & -.003 & -.0003 & -.003 & -.002 \\
\hline & .008 & .001 & .005 & .005 \\
\hline Controls & Yes & Yes & Yes & Yes \\
\hline Interactions & No & Yes & No & Yes \\
\hline $\mathrm{N}$ & 39428 & 39428 & 39428 & 39428 \\
\hline $\mathrm{R} 2$ & 0.002 & 0.006 & 0.003 & 0.01 \\
\hline \multicolumn{5}{|c|}{$\begin{array}{l}\text { Standard errors clustered at state level in paranthesis } \\
\text { Control group refers to placebo sector workers in the non-treated states (excluding Kerala) } \\
\text {, } \cdots *, * * \text { indicate significance at } 1,5 \text { and } 10 \% \text { significance levels }\end{array}$} \\
\hline
\end{tabular}

Table 15: Long Run : Treatment Impact at the Extensive Margin in Placebo Sector

\begin{tabular}{|c|c|c|c|c|}
\hline \multicolumn{5}{|c|}{ Outcome Variable : Probability of Employment as Domestic Worker } \\
\hline Estimation : & DiD & DiD & E-balance \& DiD & E-balance \& DiD \\
\hline \multirow[t]{2}{*}{ Post } & $-.04 * * *$ & $-.04 * * *$ & $-.04 * * *$ & $-.04 * * *$ \\
\hline & .005 & .005 & .001 & .001 \\
\hline \multirow[t]{2}{*}{ Treatment states } & .007 & .007 & $.007^{*}$ & .006 \\
\hline & 0.006 & .006 & .004 & .004 \\
\hline \multirow[t]{2}{*}{ Post*treatment states } & -.006 & -.007 & -.006 & -.006 \\
\hline & .006 & .006 & .004 & .004 \\
\hline Controls & Yes & Yes & Yes & Yes \\
\hline Interactions & No & Yes & No & Yes \\
\hline $\mathrm{N}$ & 39092 & 39092 & 39092 & 39092 \\
\hline R2 & 0.02 & 0.15 & 0.02 & 0.03 \\
\hline \multicolumn{5}{|c|}{$\begin{array}{l}\text { Standard errors clustered at state level in paranthesis } \\
*, * *, * * * \text { indicate significance at } 1,5 \text { and } 10 \% \text { significance levels }\end{array}$} \\
\hline
\end{tabular}

Table 16: Test for Parallel Trends : 1999 and 2004 Survey Rounds

\begin{tabular}{lcccc}
\hline \hline Outcome Variable : & Log Real Wages & Unemployment & Log Real Wages & Unemployment \\
Estimation : & DiD & DiD & E-balance \& DiD & E-balance \& DiD \\
Post & -.10 & .14 & .005 & .10 \\
& 0.08 & .12 & 0.04 & .09 \\
Treatment states & -.09 & -.06 & -.04 & -.07 \\
& 0.07 & .12 & 0.05 & .11 \\
Post*treatment states & 0.04 & -.05 & .04 & 0.0004 \\
& 0.07 & 0.20 & 0.07 & .21 \\
Controls & Yes & Yes & Yes & Yes \\
$\mathrm{N}$ & 2334 & 2691 & 2334 & 2691 \\
$\mathrm{R} 2$ & 0.314 & 0.01 & 0.357 & 0.0001 \\
\hline Standard errors clustered at State level in paranthesis & \\
$* * * * * *$ indicate significance at 1,5 and $10 \%$ significance levels & \\
Control group refers to domestic workers in the non-treated states (excluding Kerala) \\
\hline
\end{tabular}


Table 17: Test for Parallel Trends : MDID Estimation

\begin{tabular}{crrrrrrl}
\hline & \multicolumn{3}{c}{ Base Line (BL) } & \multicolumn{3}{c}{ Follow Up (FU) } & \multicolumn{2}{c}{ DiD } \\
\hline Outcome Variable & Control & Treated & Diff(BL) & Control & Treated & Diff(FU) & \\
Log real wages & 5.75 & 5.71 & -0.03 & 5.39 & 5.24 & $-0.14^{* *}$ & -.10 \\
& 0.03 & 0.07 & 0.07 & 0.02 & 0.05 & 0.05 & 0.09 \\
Months Unemployed & 0.57 & 0.53 & -0.04 & 0.56 & 0.48 & -0.08 & -0.04 \\
& 0.04 & 0.08 & 0.10 & 0.06 & 0.15 & 0.16 & 0.19 \\
\hline
\end{tabular}

Notes : Bootstrapped robust standard errors reported in paranthesis.

DiD indicates the difference in difference estimate of the outcome variable.

Significant at $90(*), 95(* *)$, and $99(* * *)$ percent.

Control group refers to domestic workers in the non-treated states (excluding Kerala)

Matching is done within control and treated groups separately between post and pre treatment periods

Table 18: DiD and E-balance estimations : 2009-2012

\begin{tabular}{lcccc}
\hline Outcome Variable : & Log Real Wages & Log Real Wages & Log Real Wages & Log Real Wages \\
Estimation : & DiD & DiD & E-balance \& DiD & E-balance \& DiD \\
Post & $0.31^{* * *}$ & $0.32^{* * *}$ & $0.35^{* * *}$ & $0.35^{* * *}$ \\
& 0.03 & 0.03 & 0.05 & .05 \\
Treatment states & $.19^{* *}$ & 0.18 & $0.19^{* * *}$ & $0.17^{* *}$ \\
& 0.10 & 0.11 & 0.07 & .08 \\
Post*treatment states & $-.20^{* *}$ & -0.17 & $-.22^{* *}$ & $-0.19^{*}$ \\
& 0.09 & 0.12 & 0.10 & .10 \\
Controls & Yes & Yes & Yes & Yes \\
Interactions & No & Yes & No & Yes \\
$\mathrm{N}$ & 1154 & 1154 & 1153 & 1154 \\
R2 & 0.287 & 0.341 & 0.319 & 0.403 \\
\hline Standard errors clustered at state level in paranthesis & & \\
$* * * * * *$ indicate significance at 1,5 and $10 \%$ significance levels & \\
\hline
\end{tabular}

Table 19: Short Run : Impact on Real Wages while restricting the control group to border states

\begin{tabular}{lcccc}
\hline Outcome Variable : & Log Real Wages & Log Real Wages & Log Real Wages & Log Real Wages \\
Estimation : & DiD & DiD & E-balance \& DiD & E-balance \& DiD \\
Post & -.01 & -.02 & .009 & .008 \\
& .06 & .05 & .05 & .05 \\
Treatment states & -.06 & -.10 & -.08 & $-.09^{*}$ \\
& .06 & .05 & .07 & .05 \\
Post*treatment states & $.28^{* *}$ & $.26^{* *}$ & $.26^{* * *}$ & $.27^{* * *}$ \\
& .10 & .10 & .09 & .08 \\
Controls & Yes & Yes & Yes & Yes \\
Interactions & No & Yes & No & Yes \\
$\mathrm{N}$ & 1534 & 1534 & 1534 & 1534 \\
R2 & 0.2366 & 0.3219 & 0.3248 & 0.3845 \\
\hline Standard errors clustered at State level in paranthesis & & \\
$* * * * * *$ indicate significance at 1,5 and $10 \%$ significance levels & \\
\hline
\end{tabular}


Table 20: Long Run : Impact on Real Wages while restricting the control group to border states

\begin{tabular}{lcccc}
\hline \hline Outcome Variable : & Log Real Wages & Log Real Wages & Log Real Wages & Log Real Wages \\
Estimation : & DiD & DiD & E-balance \& DiD & E-balance \& DiD \\
Post & $.29 * * *$ & $.26^{* * *}$ & $.32^{* * *}$ & $.28^{* * *}$ \\
& .05 & .03 & .06 & .05 \\
Treatment states & -.05 & $-.10^{*}$ & -.05 & $-.10^{* *}$ \\
& .05 & .05 & .06 & .05 \\
Post*treatment states & .07 & $.13^{*}$ & .05 & .12 \\
& .09 & .07 & .10 & .09 \\
Controls & Yes & Yes & Yes & Yes \\
Interactions & No & Yes & No & Yes \\
$\mathrm{N}$ & 1518 & 1518 & 1518 & 1518 \\
R2 & 0.2695 & 0.3453 & 0.3180 & 0.3964 \\
\hline
\end{tabular}

Standard errors clustered at State level in paranthesis

$*, * *, * * *$ indicate significance at 1,5 and $10 \%$ significance levels

Table 21: Summary Statistics: Full Sample (pre and post Treatment Periods)

\begin{tabular}{|c|c|c|c|c|c|c|}
\hline & Pre N & Post N & Pre Mean(s.d) & Post mean(s.d) & Post-Pre(s.e) & p-value \\
\hline \multicolumn{7}{|l|}{ Dependent Variables } \\
\hline Real Wages & 2473 & 2382 & $\begin{array}{c}304.02 \\
(294.50)\end{array}$ & $\begin{array}{c}429.48 \\
(478.23)\end{array}$ & $\begin{array}{l}129.46 \\
(11.35)\end{array}$ & $0.00^{* * * *}$ \\
\hline Log RealWages & 2358 & 2338 & $\begin{array}{c}5.49 \\
(.723)\end{array}$ & $\begin{array}{l}5.78 \\
(.76)\end{array}$ & $\begin{array}{c}.29 \\
(.021)\end{array}$ & $0.00^{* * * *}$ \\
\hline Monthsunemployed & 2472 & 2036 & $\begin{array}{c}.54 \\
(2.011)\end{array}$ & $\begin{array}{c}.29 \\
(1.12)\end{array}$ & $\begin{array}{l}-.25 \\
(.05)\end{array}$ & $0.00 * * *$ \\
\hline \multicolumn{7}{|l|}{ Covariates } \\
\hline Sex & 2473 & 2382 & $\begin{array}{c}.20 \\
(.40)\end{array}$ & $\begin{array}{c}.32 \\
(.46)\end{array}$ & $\begin{array}{c}.12 \\
(.012)\end{array}$ & $0.00^{* * * *}$ \\
\hline Age & 2473 & 2382 & $\begin{array}{c}35.84 \\
(13.70)\end{array}$ & $\begin{array}{c}37.76 \\
(12.94)\end{array}$ & $\begin{array}{l}1.92 \\
(.38)\end{array}$ & $0.00^{* * * *}$ \\
\hline Marriage & 2473 & 2382 & $\begin{array}{c}.54 \\
(.49)\end{array}$ & $\begin{array}{l}.60 \\
(.48)\end{array}$ & $\begin{array}{c}.06 \\
(.014)\end{array}$ & $0.00 * * *$ \\
\hline SC & 2473 & 2382 & $\begin{array}{l}.25 \\
(.43)\end{array}$ & $\begin{array}{l}.26 \\
(.44)\end{array}$ & $\begin{array}{c}.01 \\
(.012)\end{array}$ & 0.52 \\
\hline ST & 2473 & 2382 & $\begin{array}{l}.08 \\
(.27)\end{array}$ & $\begin{array}{l}.068 \\
(.25)\end{array}$ & $\begin{array}{l}-.012 \\
(.007)\end{array}$ & 0.11 \\
\hline $\mathrm{OBC}$ & 2473 & 2382 & $\begin{array}{l}.35 \\
(.47)\end{array}$ & $\begin{array}{c}.34 \\
(.47)\end{array}$ & $\begin{array}{c}-.01 \\
(.013)\end{array}$ & 0.48 \\
\hline LogLand Owned & 1357 & 1371 & $\begin{array}{c}2.11 \\
(1.80)\end{array}$ & $\begin{array}{c}2.25 \\
(1.85)\end{array}$ & $\begin{array}{c}0.14 \\
(.0701)\end{array}$ & $0.056^{*}$ \\
\hline LogLand Possess & 2324 & 2164 & $\begin{array}{c}1.58 \\
(1.49)\end{array}$ & $\begin{array}{c}1.71 \\
(1.54)\end{array}$ & $\begin{array}{l}0.13 \\
(.045)\end{array}$ & $0.0056^{* \cdots *}$ \\
\hline Illiterate & 2473 & 2382 & $\begin{array}{l}.51 \\
(.49)\end{array}$ & $\begin{array}{c}.39 \\
(.48)\end{array}$ & $\begin{array}{c}-.12 \\
(.014)\end{array}$ & $0.00^{* * * *}$ \\
\hline Just Literate & 2473 & 2382 & $\begin{array}{l}.03 \\
(.19)\end{array}$ & $\begin{array}{c}.01 \\
(.105)\end{array}$ & $\begin{array}{l}-.02 \\
(.004)\end{array}$ & $0.00^{* * * *}$ \\
\hline Primary & 2473 & 2382 & $\begin{array}{l}.25 \\
. .43)\end{array}$ & $\begin{array}{c}.32 \\
(.46)\end{array}$ & $\begin{array}{c}.07 \\
(.012)\end{array}$ & $0.00^{* * * *}$ \\
\hline Middle & 2473 & 2382 & $\begin{array}{l}.16 \\
(.36)\end{array}$ & $\begin{array}{c}.23 \\
(.42)\end{array}$ & $\begin{array}{c}0.07 \\
(.011)\end{array}$ & $0.00^{* * * *}$ \\
\hline Higher & 2473 & 2382 & $\begin{array}{c}.02 \\
(.15)\end{array}$ & $\begin{array}{c}.04 \\
(.19)\end{array}$ & $\begin{array}{c}.02 \\
(.005)\end{array}$ & $0.0011 * * *$ \\
\hline
\end{tabular}


Table 22: Summary Statistics: Comparing Sample Means for Treatment States (pre and post treatment period)

\begin{tabular}{|c|c|c|c|c|c|c|}
\hline & Pre N & Post N & Pre Mean(s.d) & Post mean(s.d) & Post-Pre(s.e) & p-value \\
\hline \multicolumn{7}{|l|}{ Dependent Variables } \\
\hline Real Wages & 488 & 467 & $\begin{array}{c}277.04 \\
(240.67)\end{array}$ & $\begin{array}{c}402.99 \\
(284.54)\end{array}$ & $\begin{array}{l}125.95 \\
(17.02)\end{array}$ & $0.00 * * *$ \\
\hline Log RealWages & 476 & 465 & $\begin{array}{c}5.41 \\
(.652)\end{array}$ & $\begin{array}{l}5.78 \\
(.68)\end{array}$ & $\begin{array}{c}0.37 \\
(.043)\end{array}$ & $0.00 * * *$ \\
\hline Monthsunemployed & 488 & 410 & $\begin{array}{c}.30 \\
(1.57)\end{array}$ & $\begin{array}{c}.12 \\
(.62)\end{array}$ & $\begin{array}{c}-.18 \\
(.082)\end{array}$ & $0.02^{* * *}$ \\
\hline \multicolumn{7}{|l|}{ Covariates } \\
\hline Sex & 488 & 467 & $\begin{array}{c}.20 \\
(.40)\end{array}$ & $\begin{array}{c}.32 \\
(.47)\end{array}$ & $\begin{array}{c}.12 \\
(.028)\end{array}$ & $0.00 * * *$ \\
\hline Age & 488 & 467 & $\begin{array}{c}34.78 \\
(13.11)\end{array}$ & $\begin{array}{c}37.70 \\
(12.42)\end{array}$ & $\begin{array}{l}2.92 \\
(.82)\end{array}$ & $0.0004 * * *$ \\
\hline Marriage & 488 & 467 & $\begin{array}{c}.60 \\
(.48)\end{array}$ & $\begin{array}{c}.65 \\
(.475)\end{array}$ & $\begin{array}{c}.05 \\
(.03)\end{array}$ & 0.103 \\
\hline SC & 488 & 467 & $\begin{array}{c}.16 \\
(.37)\end{array}$ & $\begin{array}{c}.22 \\
(.416)\end{array}$ & $\begin{array}{c}.06 \\
(.02)\end{array}$ & $0.02 * *$ \\
\hline ST & 488 & 467 & $\begin{array}{l}.07 \\
(.26)\end{array}$ & $\begin{array}{l}.051 \\
(.22)\end{array}$ & $\begin{array}{l}-.019 \\
(.015)\end{array}$ & 0.15 \\
\hline OBC & 488 & 467 & $\begin{array}{c}.51 \\
(.50)\end{array}$ & $\begin{array}{c}.57 \\
(.494)\end{array}$ & $\begin{array}{l}.06 \\
(.03)\end{array}$ & $0.05 * *$ \\
\hline LogLand Owned & 200 & 216 & $\begin{array}{c}2.24 \\
(2.10)\end{array}$ & $\begin{array}{c}2.26 \\
(2.015)\end{array}$ & $\begin{array}{c}.02 \\
(.201)\end{array}$ & 0.93 \\
\hline LogLand Possess & 450 & 440 & $\begin{array}{c}1.39 \\
(1.45)\end{array}$ & $\begin{array}{c}1.38 \\
(1.36)\end{array}$ & $\begin{array}{c}-.01 \\
(.094)\end{array}$ & 0.98 \\
\hline Illiterate & 488 & 467 & $\begin{array}{l}.68 \\
(.46)\end{array}$ & $\begin{array}{c}.54 \\
(.49)\end{array}$ & $\begin{array}{c}-.14 \\
(.031)\end{array}$ & $0.00 * * *$ \\
\hline Just Literate & 488 & 467 & $\begin{array}{c}.02 \\
(.14)\end{array}$ & $\begin{array}{c}.01 \\
(.103)\end{array}$ & $\begin{array}{c}-.01 \\
(.008)\end{array}$ & 0.22 \\
\hline Primary & 488 & 467 & $\begin{array}{l}.157 \\
(.36)\end{array}$ & $\begin{array}{c}.21 \\
(.409)\end{array}$ & $\begin{array}{l}.054 \\
(.025)\end{array}$ & $0.030 * *$ \\
\hline Middle & 488 & 467 & $\begin{array}{c}.12 \\
(.33)\end{array}$ & $\begin{array}{c}.20 \\
(.407)\end{array}$ & $\begin{array}{c}.08 \\
(.024)\end{array}$ & $0.0008 * * *$ \\
\hline Higher & 488 & 467 & $\begin{array}{l}.004 \\
(.06)\end{array}$ & $\begin{array}{c}.02 \\
(.15)\end{array}$ & $\begin{array}{c}.016 \\
(.007)\end{array}$ & $0.0095 * * *$ \\
\hline
\end{tabular}

Standard deviation and standard errors reported in paranthesis

$*, * *, * * *$ indicate significance at 1,5 and $10 \%$ significance levels

Table 23: Short Run: MDID Results-Clustering with Interactions

\begin{tabular}{rrrrrrrl}
\hline & \multicolumn{3}{c}{ Base Line (BL) } & \multicolumn{3}{c}{ Follow Up (FU) } & DiD \\
\hline Outcome Variable & Control & Treated & Diff(BL) & Control & Treated & Diff(FU) & \\
Log real wages & 4.68 & 4.57 & $-0.109^{* * * *}$ & 4.69 & 4.84 & 0.15 & $0.26^{* *}$ \\
& 0.37 & 0.37 & 0.053 & 0.38 & 0.41 & 0.119 & 0.11 \\
Months Unemployed & 0.09 & 0.05 & -0.04 & -0.22 & -0.34 & -0.11 & -0.075 \\
& 1.006 & 1.08 & 0.22 & 1.032 & 1.027 & 0.09 & 0.24 \\
\hline
\end{tabular}

Notes : Clustered robust standard errors reported in paranthesis.

Number of clusters is 33

We also include interactions between covariates on which the data is matched as controls

DiD indicates the difference in difference estimate of the outcome variable.

Significant at $90(*), 95\left(^{* *}\right)$, and $99(* * *)$ percent. 
Table 24: Short Run: MDID Results-Clustering with State dummies

\begin{tabular}{crrrrrrr}
\hline & \multicolumn{3}{c}{ Base Line (BL) } & \multicolumn{3}{c}{ Follow Up (FU) } & \multicolumn{1}{c}{ DiD } \\
\hline Outcome Variable & Control & Treated & Diff(BL) & Control & Treated & Diff(FU) & \\
Log real wages & 6.13 & 5.69 & $-0.44^{* * *}$ & 6.27 & 6.14 & -0.12 & $0.312^{* *}$ \\
& 0.03 & 0.03 & 0.04 & 0.02 & 0.108 & 0.11 & 0.15 \\
Months Unemployed & 0.19 & 0.21 & 0.02 & -0.14 & -0.101 & 0.04 & 0.02 \\
& 0.08 & 0.03 & 0.09 & 0.06 & 0.138 & 0.15 & 0.22 \\
\hline
\end{tabular}

Notes : Clustered robust standard errors reported in paranthesis.

Number of clusters is 33

Here we include only state dummies as controls

DiD indicates the difference in difference estimate of the outcome variable.

Significant at $90(*), 95(* *)$, and $99(* * *)$ percent.

Table 25: Short Run: MDID Results-Clustering with State dummies and Interactions

\begin{tabular}{crrrrrrl}
\hline & \multicolumn{3}{c}{ Base Line (BL) } & \multicolumn{3}{c}{ Follow Up (FU) } & DiD \\
\hline Outcome Variable & Control & Treated & Diff(BL) & Control & Treated & Diff(FU) & \\
Log real wages & 4.39 & 4.59 & 0.2 & 4.4 & 4.86 & 0.45 & $0.26^{* * *}$ \\
& 0.29 & 0.34 & 0.26 & 0.31 & 0.401 & 0.31 & 0.12 \\
Months Unemployed & -1.02 & -0.67 & 0.35 & -1.4 & -1.04 & 0.36 & 0.008 \\
& 1.03 & 1.05 & 0.97 & 1.01 & 1.033 & 0.92 & 0.24 \\
\hline Notes : Clustered robust standard errors reported in paranthesis. \\
Number of clusters is 33 \\
Here we include both state dummies and interactions as controls \\
DiD indicates the difference in difference estimate of the outcome variable. \\
Significant at 90 $(*), 95(* *)$, and 99 $(* * *)$ percent. \\
\hline
\end{tabular}

Table 26: A Snapshot of Treatment States

\begin{tabular}{rrrrr}
\hline Indicator & Andhra Pradesh & Bihar & Karnataka & Rajasthan \\
\hline Population (in millions) & 49.3 & 103.8 & 61.1 & 68.6 \\
Urban Population Percentage (2011 census) & 33.36 & $11.30 \%$ & $38.57 \%$ & $24.89 \%$ \\
Population Density ( per km square) & 308 & 1102 & 319 & 201 \\
Sex Ratio & 993 & 916 & 968 & 926 \\
Per Capita Income (Rs.) & 60703 & 19205 & 62251 & 44709 \\
HDI Ranking 2007-08** & $15(15)$ & $21(19)$ & $12(12)$ & $17(14)$ \\
Literacy Rates (2011) & $67 \%$ & $61.80 \%$ & $75.36 \%$ & $66.11 \%$ \\
\hline
\end{tabular}

** India Human Development Report 2011 (Figures in parantheses show HDI ranking during 1999-2000); Unless stated otherwise, data is obtained from Census 2011. 
Figure 3: Map of India-Treatment and Control States

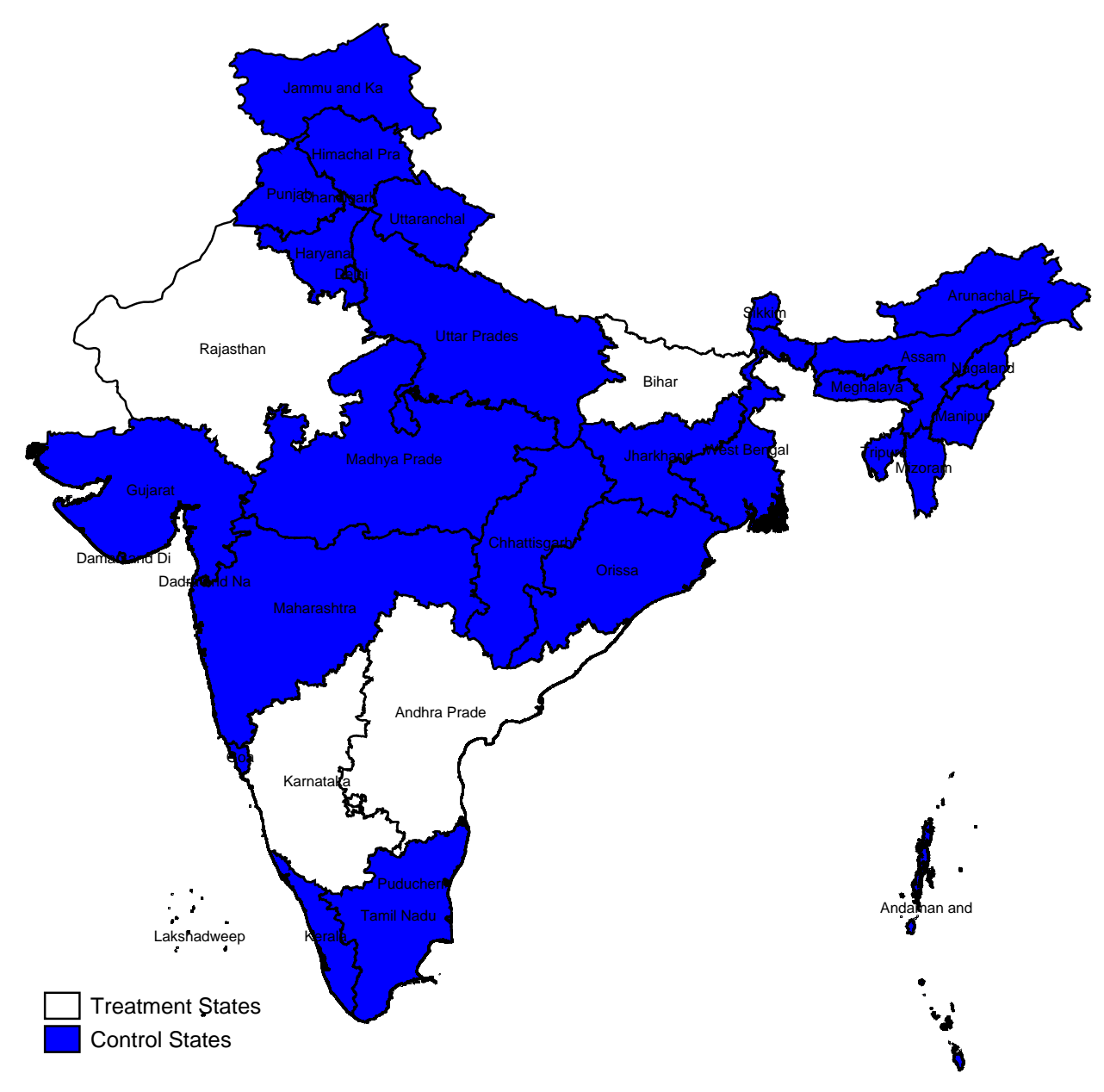


Figure 4: Pretreatment Kernel Density of Log Real Wage Distribution in Treatment and Control States

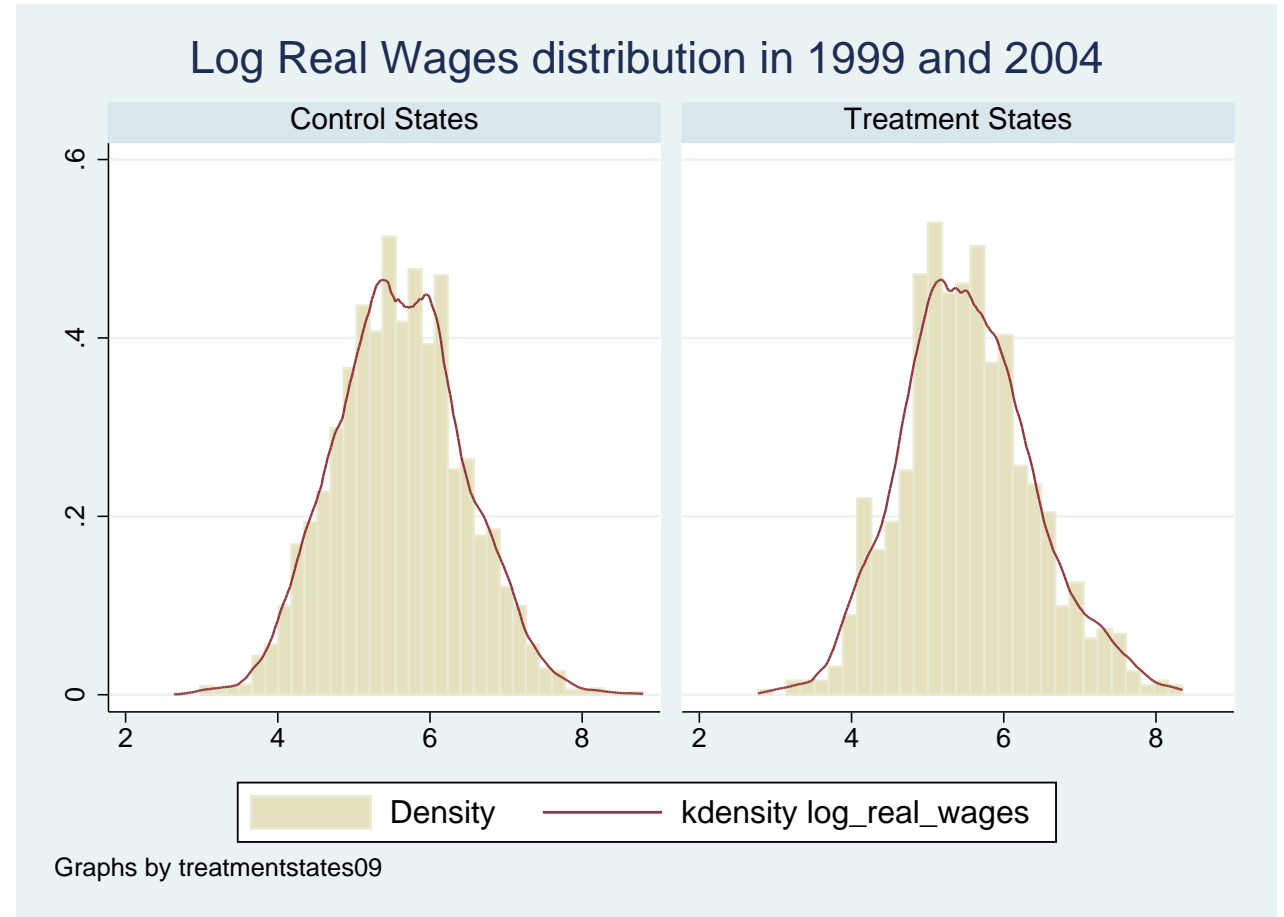

Figure 5: Pretreatment Trend of Months Unemployed in Treatment and Control States

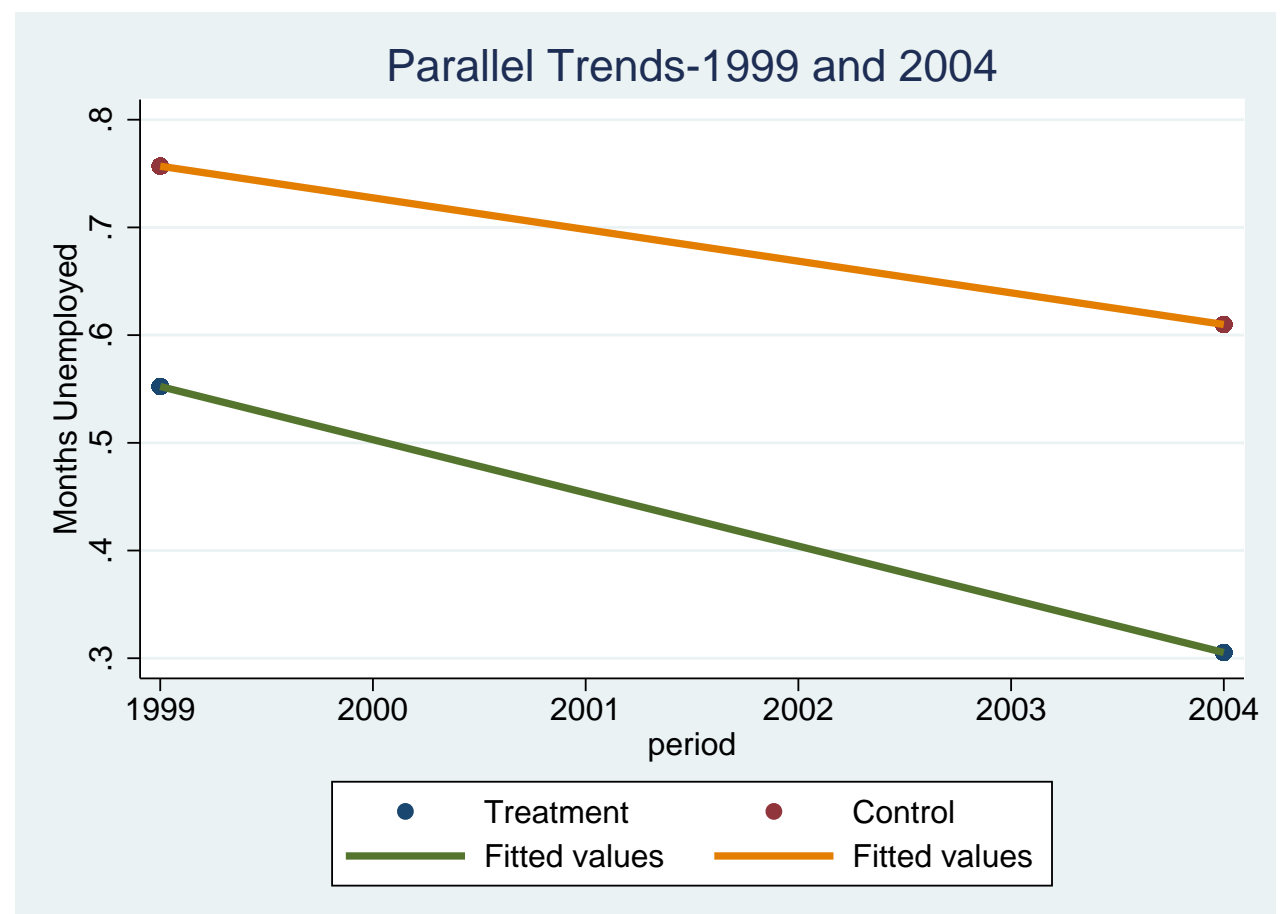

